\title{
Exploring IRSL50 fading variability in bedrock feldspars and implications for OSL thermochronometry
}

\author{
Pierre G. Valla ${ }^{1,2^{*}}$, Sally E. Lowick ${ }^{3}$, Frédéric Herman ${ }^{1}$, Jean-Daniel Champagnac ${ }^{2,4}$, Philippe \\ Steer ${ }^{5}$ and Benny Guralnik ${ }^{2,6}$ \\ 1 Institute of Earth Surface Dynamics, University of Lausanne, 1015 Lausanne, Switzerland \\ 2 Department of Earth Sciences, ETH Zürich, 8092 Zürich, Switzerland \\ 3 Institute of Geological Sciences, University of Bern, 3012 Bern, Switzerland \\ 4 Free University of Leysin, 1854 Leysin, Switzerland \\ 5 Géosciences Rennes, CNRS UMR 6118, Université de Rennes 1, 35042 Rennes, France \\ 6 Soil Geography and Landscape group and the Netherlands Centre for Luminescence Dating, \\ Wageningen University, 6708 Wageningen, The Netherlands \\ * Corresponding author, E-mail: pierre.valla@unil.ch
}

\begin{abstract}
Optically Stimulated Luminescence (OSL) is a well-established Quaternary dating method, which has recently been adapted to application in low-temperature thermochronometry. The Infra-Red Stimulated Luminescence (IRSL) of feldspar, which so far is the most promising target signal in thermochronometry, is unfortunately prone to anomalous fading. The fading of feldspar IRSL is at times not only challenging to measure, but also laborious to incorporate within luminescence growth models. Quantification of IRSL fading is therefore a crucial step in OSL thermochronometry, raising questions regarding (i) reproducibility and reliability of laboratory measurements of fading, as well as (ii) the applicability of existing fading models to quantitatively predict the level of IRSL field saturation in nature. Here we investigate the natural luminescence signal and anomalous fading of IRSL measured at $50{ }^{\circ} \mathrm{C}$ (IRSL50) in 32 bedrock samples collected from a variety of lithologies and exhumation settings (Alaska and Norway). We report a large span of IRSL50 fading rates between samples ( $\mathrm{g}_{2 \text { days }}$ ranging from $\sim 0.5$ to $\sim 45 \% /$ decade), which further demonstrates (i) a good reproducibility between two common fading measurement protocols, and (ii) the ability of tunnelling models to predict the level of feldspar IRSL 50 field saturation in nature. We observe higher IRSL50 fading in feldspar with increasing $\mathrm{Ca}$ content, although other factors cannot be dismissed at present. Finally, our dataset confirms that the applicability of feldspar IRSL50 in OSL thermochronometry is limited to rapidly-exhuming settings or warm subsurface environments.
\end{abstract}


Keywords: luminescence, feldspar IRSL, anomalous fading, OSL thermochronometry

\section{Introduction}

\subsection{OSL thermochronometry}

Understanding the processes operating at the Earth's surface requires quantitative methods to measure erosion and sedimentation rates. In that context, low-temperature thermochronometric methods (see Reiners and Brandon, 2006 for a review) have been increasingly used over the past decades to quantify bedrock cooling histories within the top 2$8 \mathrm{~km}$ of the upper crust, and subsequently to interpret them into exhumation histories (e.g. Braun et al., 2006; 2012). However, linking long-term exhumation rates $\left(10^{5}-10^{8}\right.$ year timescales) to short-term erosion measurements $\left(10^{0}-10^{3}\right.$ year timescales $)$ remains challenging, because different spatial scales and processes are involved. An ongoing debate (Herman and Champagnac, 2016; Willenbring and Jerolmack, 2016), regarding the impact of Quaternary climate and glacial/interglacial oscillations on global-scale erosion rates, highlights the current shortage of quantitative estimates of bedrock erosion and relief evolution over Quaternary to sub-Quaternary timescales (e.g. Herman et al., 2013; Champagnac et al., 2014). Recent methodological developments of low-temperature thermochronometers, such as ${ }^{4} \mathrm{He} /{ }^{3} \mathrm{He}$ (Shuster and Farley, 2005) and Optically Stimulated Luminescence (OSL) (Guralnik et al., 2015a; King et al., 2016), offer an unprecedented resolution to constrain rock cooling histories within the upper $\sim 1-3 \mathrm{~km}$ of the Earth's crust, and thus to potentially reconstruct erosion histories and/or topographic relief changes over sub-Quaternary timescales (e.g. Shuster et al., 2005; 2011; Valla et al., 2011a; King et al., 2016).

OSL dating (e.g. Aitken, 1998) has recently been adapted for low-temperature thermochronometry by considering the competing effects of filling and emptying of naturallyoccurring electron traps (linked to the OSL signal) in crystal lattices due to environmental radiation and temperature, respectively (Herman et al., 2010; Li and Li, 2012; Guralnik et al., 2013; King et al., 2016). While other "trapped charge dating" methods (e.g. Grün, 2001) have been proposed and tested, including thermoluminescence (TL; e.g. Prokein and Wagner, 1994; Tang and Li, 2015) and electron-spin resonance (ESR; Koshchug and Solovyov, 1998; Grün et al., 1999), the advantage of OSL techniques in thermochronometry lies in their rapid methodological development and expanding use in Quaternary science (see reviews by Wintle, 2008 and Rhodes, 2011). One major intrinsic limitation in trapped charge dating, common to OSL, ESR and TL alike, is signal saturation (i.e. when all available electron traps become 
filled). If the target luminescence signal for dating is close to its saturation limit, only minimum ages may be provided. Consequently, when luminescence is used to decipher rock cooling rates, near-saturation signals can only characterise maximum (upper-bound) rates of cooling and exhumation (e.g. Guralnik et al., 2013). Fortunately, the first OSL-thermochronometry applications (Herman et al., 2010; Wu et al., 2012; De Sarkar et al., 2013; Wu et al., 2015) addressed settings of extremely rapid exhumation (where signal saturation should not be a problem), and quantified bedrock cooling histories below $\sim 100{ }^{\circ} \mathrm{C}$ and over sub-Quaternary timescales. Despite the fact that a standard mineral/signal pair was chosen (quartz "fast OSL component"; Wintle and Murray, 2006), the low sensitivity (Herman et al., 2010; Jeong and Choi, 2012), anomalous characteristics ( $\mathrm{Li}$ and Li, 2006; Preusser et al., 2009), and the ubiquitous lack of the "fast component" in bedrock quartz of different petrology/mineralogy (Guralnik et al., 2015b), appeared to narrow the use of bedrock quartz for OSLthermochronometry, and stimulated the continued search for alternative mineral/signal combinations (Guralnik et al., 2015b).

Infra-Red Stimulated Luminescence (IRSL) from feldspar is advantageous over quartz in several ways (e.g. Huntley and Lamothe, 2001), with (i) a higher luminescence sensitivity in both sediment and bedrock samples (e.g. King et al., 2014), (ii) in general, a higher charge storage capacity (i.e. later saturation) offering a wider dating range (e.g. Buylaert et al., 2012), and (iii) a negligible signal contamination from quartz OSL, if present (e.g. Sohbati et al., 2013). Recently, OSL thermochronometry using bedrock Na-feldspar was investigated in a deep continental drillhole (Guralnik et al., 2015a), where IRSL signals measured at $50{ }^{\circ} \mathrm{C}$ (hereafter IRSL50) were successfully characterised in the laboratory and translated into environmental palaeotemperatures in the $\sim 40-70{ }^{\circ} \mathrm{C}$ range over a $\sim 50$ ka timescale (Guralnik et al., 2015a). Moreover, the recently-introduced protocol of multiple elevated temperature postIR (MET-pIRIR) measurement of feldspar ( $\mathrm{Li}$ and $\mathrm{Li}, 2011 \mathrm{a}, \mathrm{b}$ ) conceptually offers access to multiple thermochronometric subsystems within a single mineral, as the different subsignals display higher thermal stabilities with increasing stimulation temperatures ( $\mathrm{Li}$ and $\mathrm{Li}, 2011 \mathrm{~b}$; King et al., 2016).

\subsection{Anomalous fading in feldspar IRSL}

Although feldspar IRSL appears in many ways preferable to quartz OSL for thermochronometry, one of the drawbacks of feldspar IRSL is its anomalous fading (e.g. Spooner, 1994; Huntley and Lamothe, 2001), an athermal loss of trapped electrons via quantum 
mechanical tunnelling to their nearest recombination centres (Visocekas, 2002; Huntley, 2006). Since anomalous fading is ubiquitous in feldspar IRSL50 (Huntley and Lamothe, 2001; Huntley and Lian, 2006), recent efforts have mainly focused on extracting a more stable feldspar signal using pIRIR protocols (e.g. Thomsen et al., 2008; 2011; Li and Li, 2011a; Buylaert et al., 2012). Although the latter protocols exhibit a reduced, perhaps even negligible, anomalous fading, it is generally at the expense of a higher thermal stability of the target electron trap ( $\mathrm{Li}$ and Li, 2011a,b; Guralnik et al., 2015c; King et al., 2016). This in turn leads to higher residual doses in sediment dating (e.g. Wintle, 2008), and higher closure temperatures in thermochronometry (e.g. Guralnik et al., 2015c), which may once again limit the benefit of non-fading IRSL signals in low-temperature thermochronometry (e.g. Qin et al., 2015). Moreover, the MET-pIRIR protocol often exhibits progressively lower IRSL sensitivity with increasing stimulation temperature ( $\mathrm{Li}$ and $\mathrm{Li}, 2011$; King et al., 2016), which can hinder signal extraction for some bedrock samples with low luminescence sensitivity. Despite the presence of anomalous fading in feldspar IRSL50, and in light of recent success in avoiding it via pulsed stimulation at low temperature (Tsukamoto et al., 2006; Jain et al., 2015a), IRSL50 remains highly relevant for OSL thermochronometric investigations.

Over the years, several protocols have been proposed to quantify the anomalous fading of feldspar over laboratory timescales (Huntley and Lamothe, 2001; Auclair et al., 2003) and to correct for fading in the linear dose response range (e.g. Lamothe and Auclair, 1999; Huntley and Lamothe, 2001; Lamothe et al., 2003). More recently, Huntley (2006) formulated a physical description of electron tunnelling that further enabled the application of fading corrections within the entire dose response range (Kars et al., 2008; Li and Li, 2008). In particular, these models allow the prediction of luminescence intensities in "field saturation" (Huntley and Lian, 2006), in which the natural intensity of feldspar IRSL50 becomes insensitive to time, and is governed only by the counterbalancing effects of environmental radiation and anomalous fading (Kars et al., 2008).

In the present study, we investigate anomalous fading of the IRSL50 signal in bedrock feldspar, and highlight its key implications for OSL thermochronometry. As described earlier, OSL thermochronometry exploits the thermal dependence of trapped electrons in minerals during their exhumation towards the Earth's surface. Given zero fading, a non-saturated natural IRSL50 signal in bedrock feldspar should, in theory, reflect the sample's cooling history. Anomalous fading of the signal would, however, lower the measured IRSL50 level in a given 
bedrock sample, preventing full saturation of the signal and influencing the determination of a cooling rate (if not accounted for). While the incorporation of the effects of IRSL50 fading in OSL-thermochronometric interpretation has been demonstrated as important (Guralnik et al., 2015a; King et al., 2016), there is a lack of consensus at present, as to whether laboratory measurements of IRSL fading are reproducible and/or reliable (see Li et al., 2014 for a review), and thus whether the use of fading models (and their associated age correction schemes) is appropriate. Moreover, the recent notion that all luminescence processes in feldspars are intrinsically related to fading (Jain et al., 2012; 2015b) raises a renewed interest in the fading model of Huntley (2006) and its later derivatives. More specifically, it raises the need for validation studies, where a laboratory measurement of fading rate can be related to its natural fading rate in nature. To date, only a handful of studies (Huntley and Lian, 2006; Kars et al., 2008; Guralnik et al., 2015a) have quantitatively evaluated the effects of natural versus laboratory fading rates. It is therefore necessary to assess (i) whether anomalous fading of the feldspar IRSL50 signal can be accurately measured, and (ii) for a given fading rate, whether the field saturation of the IRSL50 signal can be quantitatively predicted. To this aim, we extracted a wide range of $\mathrm{K}$ - and $\mathrm{Ca}-/ \mathrm{Na}-\mathrm{feldspars}$ from 32 bedrock samples in different lithologies and exhumation environments, and measured their natural feldspar IRSL50 intensities alongside the anomalous fading of the laboratory-regenerated signals. A large geochemical dataset, including whole-rock major and trace elements as well as selected feldspar mineralogy, enables us to discuss potential causes for the wide range of IRSL 50 anomalous fading observed. Finally, we use this dataset to test the theoretical ability of tunnelling models (Huntley 2006; Kars et al., 2008; Guralnik et al., 2015a,c) to predict IRSL50 field saturation levels, and to discuss the implications for OSL thermochronometry.

\section{Samples and methods}

\subsection{Sampling strategy and sample preparation}

Bedrock samples from old crystalline or metamorphic basements have been collected in different exhumation settings in Norway and Alaska to explore the applicability of feldspar IRSL $_{50}$ thermochronometry over a wide range of long-term (i.e. $10^{5}-10^{8}$ years) exhumation rates. All sample locations and lithological descriptions are given in Table 1. Eight samples are distributed along the Sognefjord and its vicinity (SOG samples; western Norway) where exhumation rates are $\sim 0.01-0.05 \mathrm{~km} \mathrm{Ma}^{-1}$ (e.g. Hendriks et al., 2007; Nielsen et al., 2009). The SOG samples were collected at varying elevations, from sea-level towards $\sim 1000-\mathrm{m}$ a.s.l. lowrelief surfaces (e.g. Steer et al., 2012). Fifteen samples have been collected in the Granite 
Range (GRA samples; southern Alaska) where low-temperature thermochronometric data indicates long-term exhumation rates of 0.1-0.5 $\mathrm{km} \mathrm{Ma}^{-1}$ (e.g. Spotila et al., 2004; Berger et al., 2008). In the Granite Range, our sampling strategy was to collect bedrock samples across elevation profiles (Wagner and Reimer, 1972; Valla et al., 2011b). Finally, nine samples have been collected in the Yakutat terrain (YAK samples; southern Alaska), all locations at sea-level along the Disenchantment Bay - Russel Fjord. This area is tectonically active with reported long-term exhumation rates of $\sim 1-3 \mathrm{~km} \mathrm{Ma}^{-1}$ (e.g. McAleer et al., 2009; Enkelmann et al., 2015). Our sampling strategy thus covers two orders of magnitude of long-term bedrock exhumation rates, from $0.01 \mathrm{~km} \mathrm{Ma}^{-1}$ (SOG) up to 1-3 $\mathrm{km} \mathrm{Ma}^{-1}$ (YAK). Moreover, we targeted different lithologies (sandstone, gneiss and granite/diorite samples), probing a large diversity in bedrock geochemistry and consequently also in feldspar mineralogy. Finally, we restricted our study to cold environments (mean annual surface temperatures $<10{ }^{\circ} \mathrm{C}$, Table 1 ) to exclude potential luminescence signal loss at surface temperature conditions in tropical to sub-tropical regions (Wu et al., 2015).

Bedrock samples were prepared under subdued orange light to ensure the extraction of feldspar minerals from the interior of the sample, where the luminescence signal is unaffected by surface bleaching. Initial sample dimensions were at least $10 \mathrm{~cm}$ (length/width/thickness) to allow the removal of the light-exposed sample surface (at least 2-3 cm) using a water-cooled diamond saw. The light-safe internal part was then gently hand crushed to 180-212 $\mu \mathrm{m}$ grain size using a mortar and pestle to avoid mineral grinding and potential luminescence resetting via triboluminescence (e.g. Bateman et al., 2012). All 180-212 $\mu \mathrm{m}$ grains were treated with $32 \%$ hydrochloric acid to remove potential surface carbonates and with $30 \%$ hydrogen peroxide to remove any organic component. After chemical treatment, mineral fractions were rinsed thoroughly with water to remove dust particles. Feldspar and quartz fractions were isolated by density separation using LST Fastfloat (sodium heteropolytungstate). Densities of $2.58 \mathrm{~g} \mathrm{~cm}^{-3}$ and $2.70 \mathrm{~g} \mathrm{~cm}^{-3}$ were used in order to isolate potassium-rich feldspars (K-feldspars, $\left.<2.58 \mathrm{~g} \mathrm{~cm}^{-3}\right)$ from quartz and other feldspars $\left(2.58-2.70 \mathrm{~g} \mathrm{~cm}^{-3}\right)$, and from remaining heavy minerals $\left(>2.70 \mathrm{~g} \mathrm{~cm}^{-3}\right.$ ). For SOG samples (except SOG-22) we selected K-feldspars for analysis.

For GRA, YAK and SOG-22 samples, density separation at $2.58 \mathrm{~g} \mathrm{~cm}^{-3}$ yielded no light fraction, suggesting the dominance of calcium/sodium-plagioclases (Ca-/Na-feldspars), which were thus taken for further analysis. Further mineral purification was deemed unnecessary, as the contribution from quartz to IRSL50 is negligible (Sohbati et al., 2013 and references 
therein). Feldspar extracts were not etched before luminescence measurements (Duller, 1992), and feldspar grains were directly mounted on stainless steel discs to produce large aliquots (4 to $6 \mathrm{~mm}$ diameter, $\sim 500-1500$ grains per disc).

\subsection{Luminescence equipment and protocols}

All IRSL50 measurements were made on automated Ris $\varnothing$ TL/OSL DA-20 readers (Institute of Geological Sciences, University of Bern), each possessing a ${ }^{90} \mathrm{Sr} /{ }^{90} \mathrm{Y}$ beta source $(\sim 0.1-0.2$ $\left.\mathrm{Gy} \mathrm{s}^{-1}\right)$ and a heater plate $\left(20-700{ }^{\circ} \mathrm{C}\right)$, with systematic instrumental uncertainties of $\sim 1.5 \%$ for single-aliquot measurements (Bøtter-Jensen et al., 2010). Luminescence stimulation was performed with infrared $(870 \pm 40 \mathrm{~nm})$ light-emitting diodes at $90 \%$ power (delivering $\sim 130$ $\mathrm{mW} \mathrm{cm} \mathrm{c}^{-2}$ at the aliquot position); the emitted luminescence signal was detected through a 410 $\mathrm{nm}$ interference and a 2-mm Schott BG-39 filters by an EMI 9235QA photomultiplier tube. All luminescence protocols described below (adapted from Guralnik, 2015a) are fully detailed in Table 2.

Feldspar natural IRSL50 signals, and their subsequent laboratory dose-response curves, were measured using the Single-Aliquot Regenerative-dose (SAR) protocol (Wallinga et al., 2000). For each sample, at least three individual aliquots were measured using a preheat at $250{ }^{\circ} \mathrm{C}$ for $60 \mathrm{~s}$ (to empty unstable electron traps), followed by IRSL50 for $200 \mathrm{~s}$ (Table 2). We used laboratory beta irradiation doses from 0 up to $\sim 2800$ Gy to fully characterize the dose response curve, a test dose of 44 Gy to monitor sensitivity changes throughout the protocol, and a hightemperature optical wash (IRSL at $290{ }^{\circ} \mathrm{C}$ ) between measurement cycles (Buylaert et al., 2009). Given the recent interest in and the research into "test dose plateaus" (Yi et al., in press), we believe that a test dose of $44 \mathrm{~Gy}$ is readily applicable to obtain equivalent doses in the $\sim 4.4-$ 440 Gy range (cf. Yi et al., in press), and likely even beyond. While small variations in the laboratory saturation level as a function of test dose have also been documented (Yi et al., in press), these effects are demonstrably minor and were hence considered beyond the scope of the present study.

All analysed aliquots fulfilled the standard performance criteria for recuperation $(<5 \%)$, recycling ratio $(<10 \%)$ and maximum test dose error $(<10 \%)$. To test the efficacy of the SAR protocol parameters, a dose recovery experiment was conducted for each sample (Supplementary Table S5). To this end, two to three fresh aliquots per sample were optically bleached using IRSL50 for $300 \mathrm{~s}$, and were subsequently given a 200-Gy laboratory dose which 
was then treated as an unknown and recovered using the same SAR protocol as the natural doses.

To explore the fading variability of IRSL50 signals in individual bedrock samples, we conducted fading experiments on two sensitised aliquots from the dose response experiments. We used two different approaches to measure feldspar IRSL50 fading (Table 2), namely a SARbased long-shine method (modified from Huntley and Lamothe, 2001), and a non-SAR shortshine method (modified from Auclair et al., 2003), with the objective to test the agreement between the two protocols. In the long-shine protocol, after a given dose of $200 \mathrm{~Gy}$, the luminescence signal was measured following variable delays, each lasting between 0.3 and 48 hours (Table 2). In the short-shine protocol, a dose of 72 Gy was given only once, and followed by a series of consecutive short-shine $(0.1 \mathrm{~s})$ measurements, separated from each other by pauses lasting between 0.1 and 55 hours. To account for signal loss due to the short optical excitation, the delayed short-shine measurements were normalized to an otherwise identical series of prompt (undelayed) measurements, done once before and once after the delayed experiment (Table 2).

\subsection{Geochemistry and environmental dose rate determination}

We obtained the whole-rock geochemistry (major and trace elements) of all 32 samples using inductively-coupled plasma mass spectrometry (Supplementary Tables S2-S3) to measure the dominant radionuclide content used for the environmental dose rate estimate (U, Th and K, Table 1). For a subset of 12 samples (GRA and YAK), we used the X-ray fluorescence (XRF) attachment to the Ris $\varnothing$ TL/OSL reader (Kook et al., 2012; Guralnik et al., 2015a) to determine feldspar mineralogical composition (Supplementary Table S4) and infer the internal potassium content ( $K_{\text {int }}$, Tables 1 and S4). XRF data confirms that, in GRA and YAK samples, the aliquot mineralogy is dominated by $\mathrm{Ca}-\mathrm{Na}$-feldspars (with up to $50 \%$ wt. quartz content), translating to an internal potassium content $K_{\text {int }}$ between 0.2 and $4 \%$ (Supplementary Table S4). Based on these measurements, we assumed for the other GRA and YAK samples (incl. SOG-22) an averaged $K_{\text {int }}$ of $1.9 \pm 1.4 \%$ (Table 1), in agreement with previous estimates reported in the literature for Ca-/Na-feldspars (Barré and Lamothe, 2010; Sohbati et al., 2013; Guralnik et al., 2015a). For SOG samples (except SOG-22), we used $K_{\text {int }}$ of $12.5 \pm 1 \%$ for K-feldspars following standard literature values (Huntley and Baril, 1997; Barré and Lamothe, 2010). 
For each sample, the whole-rock radionuclide content (U, Th and K) and feldspar $K_{\text {int }}$ have been converted into environmental dose rates using the conversion factors of Guérin et al. (2012), beta and gamma attenuation factors of Guérin et al. (2012) and Guérin and Mercier (2012), and alpha attenuation factors of Bell (1980) and Brennan et al. (1991). For alpha attenuation, an a-value of $0.15 \pm 0.05$ was used after Balescu and Lamothe (1994). The average water content in our bedrock samples was estimated at $2 \pm 2 \%$ (e.g. Aitken and Xie, 1990). Cosmic dose rate was treated as negligible, being comparable in magnitude to uncertainty on the total environmental dose rate (King et al., 2016). Based on thin-section observations, and because the original grain size has been affected by rock crushing and sieving during feldspar extraction, we used a 180-2500 $\mu \mathrm{m}$ grain size range for SOG and GRA samples and a 180-1000 $\mu \mathrm{m}$ grain size range for YAK samples.

To address the two entangled uncertainties regarding (i) the grain size of the target feldspar, and (ii) the feldspar phase which is actually contributing to the IRSL50 signal (e.g. Sohbati et al., 2013), we considered several (2 or 4, Supplementary Table S1) dose rate scenarios following the approach of Guralnik et al. (2015a). Specifically, for all feldspars, we calculated dose rates for two end-member grain sizes (180 and $2500 \mu \mathrm{m}$ for GRA and SOG, and 180 and $1000 \mu \mathrm{m}$ for YAK), assuming a homogeneous distribution of internal potassium ( $K_{\text {int }}$, Table 1) and IRSL50 signal contribution from the entire feldspar crystal. For Na-/Ca feldspars (GRA, YAK and SOG-22), we calculated two additional scenarios, in which all the IRSL50 signal originates only from K-feldspar inclusions ( 1 and $100 \mu \mathrm{m}, K_{\text {int }} \sim 12.5 \%$ ) within the Na-/Cafeldspar host crystal (e.g. Sohbati et al., 2013). We then averaged these end-member scenarios to obtain representative environmental dose rates, which ranged across more than an order of magnitude between samples, from 0.3 to $9 \mathrm{~Gy} \mathrm{ka}^{-1}$ (Table 1). This range, and the associated conservative errors, reflect the variability between K-rich and K-poor feldspar phases, and the averaging across the diverse dose-rate scenarios as listed above (Supplementary Table S1).

\section{Results}

3.1. Dose response and fading measurements

Dose response and fading measurements are illustrated for four representative GRA, SOG and YAK samples (Figure 1), and are fully documented for all samples in the Supplementary Information (Supplementary Table S6). Analysed aliquots (4- to 6-mm diameter) usually yielded bright signals with typical IRSL50 decay curves. Laboratory dose-response curves (left panels in Figure 1) have been fitted using the General-Order Kinetics (GOK) growth function 
(Eq. (10) in Guralnik et al., 2015c). The characteristic dose $\left(\mathrm{D}_{0}\right)$, the electron-trapping order $(\alpha)$, as well as the equivalent dose $\left(D_{e}\right)$, are reported in Tables 3 and S5. For each aliquot, we also derived the natural IRSL $\mathrm{I}_{50}$ signal $\mathrm{L}_{\mathrm{n}} / \mathrm{T}_{\mathrm{n}}$ (Figure 1) and calculated the natural trap filling level $(\mathrm{n} / \mathrm{N})_{\text {nat }}$ by multiplying the apparent IRSL50 intensity relative to its laboratory maximum (open stars in Figure 1) by the predicted number of occupiable traps in the laboratory (Eq. (3) in Guralnik et al., 2015a). The majority of best-fit $\mathrm{D}_{0}$ and $\alpha$ values are well-constrained with typical relative uncertainties of $<10 \%$ and $<4 \%$, respectively (Table 3). Natural trap filling levels $(\mathrm{n} / \mathrm{N})_{\text {nat }}$ exhibit varying uncertainties (1-70\%; clearly anticorrelated with $(\mathrm{n} / \mathrm{N})_{\text {nat }}$ itself), and cover almost three orders of magnitude (i.e. 0.003-0.85; Table 3), thus offering a robust dataset for evaluating the net effects of environmental radiation, anomalous fading and possibly long-term cooling on the natural IRSL50 intensity of bedrock feldspar.

Fading results obtained using both the long-shine (central panels in Figure 1) and shortshine (right panels in Figure 1) methods are also summarised in Table 3. Two aliquots were measured individually and averaged to calculate sample-specific g-values and standard deviations ( $\mathrm{g}_{2 \text { days }}$ in \%/decade; Huntley and Lamothe, 2001). Fitting the same datasets using Eq. (5) in Kars et al. (2008), we obtained an alternative measure of fading - the nearestneighbouring hole-centre density $\rho$ ' as defined in Huntley (2006) - which we later used in the kinetic model to predict the IRSL50 field saturation levels (Guralnik et al., 2015a). Inter-aliquot variability is small, confirming the good reproducibility of the fading measurement protocols, with more robust estimates for the long-shine method as explained below (Table 3). Although the short-shine protocol is less time-consuming (approximately half the time), the integrated IRSL $_{50}$ signal at each short-shine measurement is considerably lower, and therefore associated with larger uncertainties propagated into the resulting g-value (Table 3 and Figure 1). For feldspars with intermediate to low luminescence sensitivity (roughly one third of our dataset), the short-shine protocol yielded signals with a very low signal-to-background ratio that could not be used to derive meaningful g-values (Table 3). Figure 2 shows that, on average, fading rate estimates are in excellent agreement between the long- and the short-shine protocols. Thus, to further reduce experimental noise, in the subsequent modelling we used averaged g-values (wherever possible) from both protocols. Sample-specific IRSL50 g $_{2 \text { days }}$ values reveal a wide range from $\sim 0.5$ to $\sim 45 \% /$ decade (Table 3). K-feldspars from SOG samples exhibit $\mathrm{g}_{2 \text { days }}$ values between 3 and $11 \% /$ decade, which is typical for K-feldspars from both bedrock and sediment origin (Huntley and Lamothe, 2001; Huntley and Lian, 2006). Na-/Ca-feldspars show 
a higher variability in measured $g_{2 \text { days }}$ values between samples (Figures 2 and 3), especially for GRA samples (from 0.5 to $>45 \% /$ decade).

\subsection{Predictions of feldspar IRSL50 field saturation}

To evaluate whether fading variability in our dataset is the main controlling factor for the natural IRSL50 intensities, we first examined the relationship of the laboratory-derived $\mathrm{g}_{2 \mathrm{days}}$ values with the measured $(\mathrm{n} / \mathrm{N})_{\text {nat }}$ values (Figure 3). Our results show a clear inverse correlation between $\mathrm{g}_{2 \text { days }}$ and $(\mathrm{n} / \mathrm{N})_{\text {nat }}$ values, in agreement with previous observations (Huntley and Lian, 2006) but over a considerably wider range of fading rates. Even prior to modelling, such an inverse correlation suggests that the measured $(\mathrm{n} / \mathrm{N})_{\text {nat }}$ in most of our samples is mainly controlled by anomalous fading. Only some YAK samples appear to deviate from the overall trend, with their $(\mathrm{n} / \mathrm{N})_{\text {nat }}$ values markedly below field saturation (Figure 3). However, the relation in Figure 3 is only qualitative, because this empirical relationship might be influenced not only by sample-specific kinetic parameters, but also by thermal loss (which cannot be accounted for in this figure). In the following section, we test our current dataset against a recently proposed physical model predicting feldspar IRSL50 field saturation under anomalous fading (Guralnik et al., 2015a, incorporating the tunnelling term of Huntley, 2006, and extending the dose response of Kars et al., 2008 to non-first order).

Athermal IRSL signal loss in feldspars is caused by the quantum mechanical tunnelling of electrons from their traps towards electron holes (Huntley and Lamothe, 2001). Here we use the physical model of Huntley (2006) which is based on the assumptions that (i) the tunnelling of electrons is governed by the distance to their nearest recombination centre, and (ii) recombination centres within a feldspar crystal are randomly distributed with a given density. This model (Huntley 2006) can be used to estimate sample-specific field saturation values (e.g. Kars et al., 2008; Guralnik et al., 2015a; King et al., 2016). Following Guralnik et al. (2015a), we use a Monte-Carlo approach to numerically predict, on a sample to sample basis, the IRSL 50 trap filling saturation values in nature $(\mathrm{n} / \mathrm{N})_{\mathrm{ss}}$ (termed "field saturation"). In the simulation (1000 runs per sample), random instances of the kinetic parameters ( $\mathrm{D}_{0}$ and $\alpha$, Table 3 ), natural dose rates (Table 1), and $\rho^{\prime}$ (Table 3, averaged wherever possible between the long- and shortshine experiments) are drawn from their normal distributions (as given by their best-fit values). The modelling results, reported as median $(\mathrm{n} / \mathrm{N})_{\mathrm{ss}}$ and associated $68 \%$ confidence interval, are given in Table 3 and visualised against measured natural trap filling $(\mathrm{n} / \mathrm{N})_{\text {nat }}$ values in Figure 4. 
Figure 4 highlights the quantitative agreement between predicted $(n / N)_{s s}$ and measured $(\mathrm{n} / \mathrm{N})_{\text {nat }}$ values, confirming that most of our samples are either in full field saturation, or hardly discernible from it ( $<15 \%$; Guralnik et al., 2015b). In other words, the natural feldspar IRSL 50 signal in the majority of our samples $(n=25)$ is controlled by electron tunnelling and does not include a detectable thermal signature of the rock exhumation history. However, more than half $(66 \%)$ of YAK samples, representing the fastest-exhuming setting, exhibit $(\mathrm{n} / \mathrm{N})_{\text {nat }}$ values that are considerably (more than 15\%) below their predicted $(\mathrm{n} / \mathrm{N})_{\mathrm{ss}}$ values, suggesting field disequilibrium and thus high likelihood of a thermal signature that can be translated into a cooling history. The thermal signature of two additional samples (GRA-BR and SOG-17) remains in doubt, requiring further investigation that will either link them to exceptional thermal histories, or dismiss them as outliers (one in each locality).

\subsection{Dose recovery results}

Calculated dose recovery ratios (Supplementary Table S5) were typically within $10 \%$ of unity for all but four (GRA-13/-14/-17 and SOG-21) samples. Although imperfect, the 15-20\% underestimation in the dose recovery of SOG-21 is within familiar values, even when working with a SOL2 solar simulator (e.g. Buylaert et al., 2012; King et al., 2016), and may relate to an irreversible trapping efficiency change (Kars et al., 2014). On the other hand, it is hard to blame the considerable dose recovery overestimates in GRA-13/-14/-17 (30 to 65\%) on the test dose/given dose ratio (here 18\%), which is in the $15-80 \%$ trust zone and certainly close to the recently recommended $\sim 30 \%$ value (Yi et al., in press). To test whether the observed overestimation is due to a large residual dose, we measured the latter in GRA-13 and GRA-BR after an IRSL50 bleach for 300 s. Low residuals of $\sim 5-8$ Gy correspond to less than $2 \%$ of the equivalent doses, and to $2-3 \%$ of the recovered dose, and therefore cannot explain the observed overestimations. To test whether the problem lies in a thermal transfer (e.g. Huntley et al., 1993), we extended the dose recovery experiments further by conducting the IRSL bleach at higher temperatures $\left(100\right.$ and $\left.200{ }^{\circ} \mathrm{C}\right)$. Bleaching at higher temperatures did not significantly improve dose recovery in GRA-13/-14/-17, and had no effect on a well-behaving sample (GRA-BR). Overall, unacceptable dose recovery affects only a minor subset (13\%) of our dataset and might not necessarily imply that the obtained $(\mathrm{n} / \mathrm{N})_{\text {nat }}$ values are not reliable (Buylaert et al., 2012). However, such dose recovery over- and underestimations do raise the question of what thermal/optical bleach is most appropriate for resetting the natural IRSL50 intensity in feldspars that were never previously exposed to light. 


\section{Discussion}

4.1. IRSL50 and anomalous fading in bedrock feldspars

Our results confirm that feldspar IRSL $_{50}$ signals from bedrock extracts show consistent and reproducible luminescence characteristics using the SAR protocol. This is a clear advantage compared to OSL of bedrock quartz which, apart from a very few cases (e.g. Wu et al., 2015), is generally deemed dim and unsuitable (Jeong and Choi, 2012; Guralnik et al., 2015b). Moreover, the vast majority of our bedrock feldspars $(87 \%, \mathrm{n}=28$, Supplementary Table S5) also fulfilled the dose recovery test, which is a fundamental acceptance criterion for luminescence dating. Dose responses were successfully fitted with a General-Order Kinetics model, with a median order of $2.4 \pm 0.8$, in agreement with Na-feldspars from the KTB borehole (Guralnik et al., 2015a), therefore capturing the non-linearity of the dose response curve in just a single parameter.

Fading measurements exhibit a large variability in bedrock feldspars from $\sim 0.5$ to $\sim 45$ $\% / d e c a d e$, beyond the previously published value range (Huntley and Lamothe, 2001; Huntley and Lian, 2006). Moreover, we compared two established fading protocols in sediment dating (Huntley and Lamothe, 2001; Auclair et al., 2003) and demonstrated that both are applicable for bedrock feldspars, yielding comparable results between the two methods (Figure 2). Given the considerable experimental differences between the protocols (SAR-based and non-SAR), the agreement of the obtained results is striking. The dependence of the fading rate on the given laboratory dose (Huntley and Lian, 2006; Li and Li, 2008; Kars and Wallinga, 2009) is not evident from our dataset, although the administered laboratory doses (200 and 72 Gy for the long-shine and short-shine protocols, respectively) may be too close to detect any systematic deviation.

In our suite of bedrock feldspars, $(\mathrm{n} / \mathrm{N})_{\text {nat }}$ values are mostly inversely correlated with laboratory-measured fading rates (Figure 3), qualitatively suggesting field saturation in the majority of samples. Quantitatively, we have demonstrated that field saturation can be successfully predicted across almost three orders of magnitude of IRSL50 electron trap occupancy (Figure 4), using a recent extension (Guralnik et al., 2015c) of familiar electron tunnelling models (Huntley, 2006; Kars et al., 2008). Despite successful prediction of field saturation in both sedimentary feldspars (Kars et al., 2008; Kars and Wallinga, 2009) and bedrock feldspars (Guralnik et al., 2015a; King et al., 2016), the underlying model(s) and the ability to accurately measure the g-value in the laboratory remains a debateable subject ( $\mathrm{Li}$ et 
al., 2014). Here, we exploited the large variability in measured fading rates to provide a quantitative validation of our predictive model over a large range of dose rates, trap occupancies, and fading rates (Figure 4).

We also used the wide range of observed IRSL $_{50}$ fading rates to discuss potential geochemical control, starting with the whole-rock geochemistry (Supplementary Tables S2-3) as a first-order proxy. However, we found no convincing relationship between the whole-rock trace element content (Supplementary Table S3) and feldspar IRSL50 fading rate. Figure 5A illustrates the lithological variability within our dataset as shown by representative major oxides $\left(\mathrm{SiO}_{2}\right.$ and $\left.\mathrm{Fe}_{2} \mathrm{O}_{3}\right)$, suggesting that, at first order, the fading rate would increase with decreasing $\mathrm{SiO}_{2}$ content or increasing $\mathrm{Fe}_{2} \mathrm{O}_{3}$ (or $\mathrm{CaO}$ ) content. Felsic lithologies (i.e. >63\% wt. $\mathrm{SiO}_{2}$ content) all show relatively low feldspar fading rates (less than $10 \% /$ decade) regardless of the feldspar type. However, for intermediate (i.e. 52-63\% wt. $\mathrm{SiO}_{2}$ content) and mafic (i.e. $<52 \%$ wt. $\mathrm{SiO}_{2}$ content) lithologies, a large spread in fading rates is observed (Figure 5A). For a representative subset of GRA and YAK feldspar separates, we also performed XRF mineralogical determination (Supplementary Table S4). Figure 5B shows that the feldspar fading rate increases with $\mathrm{Ca}$ content, in agreement with previous observations (Huntley and Lian, 2006; Huntley et al., 2007). In summary, neither the whole-rock geochemistry, nor the trace elements, seem to be a good proxy for feldspar anomalous fading (although we did not apply multivariate analysis); however, our results show that the feldspar internal chemistry (i.e. $\mathrm{Ca}$ content, Figure 5B) may be a first-order proxy for the IRSL50 fading rate. Further investigations are required to better understand the potential causes of fading rate variability in bedrock feldspars; these include both internal factors (e.g. the origin of the IRSL50 signal in Ca/Na-feldspars; e.g. Sohbati et al., 2013) as well as external drivers, such as the metamorphic grade or terrain age (Huntley and Lamothe, 2001), or weathering processes (Parish, 1992; Huntley, 2011).

\subsection{Implications for OSL thermochronometry}

Our extensive bedrock dataset offers an opportunity to discuss the applicability of feldspar IRSL $_{50}$ in OSL thermochronometry. First, the variability of the fading rates measured for both $\mathrm{K}$ - and $\mathrm{Ca}-/ \mathrm{Na}$-feldspars is significantly broader than those reported in previous OSL thermochronometric studies (Guralnik et al., 2015a, King et al., 2016). This reinforces the notion that anomalous fading in feldspar should be measured for each sample, as it can strongly affect the natural IRSL50 signal (Figure 3). Moreover, one further complexity in OSL 
thermochronometry is that a sample's thermal history can be inverted only from the natural trap filling $(\mathrm{n} / \mathrm{N})_{\text {nat }}$, and not from the equivalent dose alone $\left(\mathrm{D}_{\mathrm{e}}\right)$ as in OSL sediment dating. This prevents the application of classical fading correction schemes (e.g. Huntley and Lamothe, 2001) and requires the quantitative prediction of the field saturation level of the luminescence signal (e.g. Kars et al., 2008; $\mathrm{Li}$ and $\mathrm{Li}, 2008$ ) in order to screen for a potential "thermal signature" in a given sample. For most of our samples, and within a wide range of fading rates, the quantitative agreement of observed field saturation levels of the IRSL50 signal with numerical results from the standard tunnelling model (Huntley, 2006), coupled with a GeneralOrder Kinetics dose response (Guralnik et al., 2015c), confirms the need to include fading measurements in preliminary screening of samples before any thermochronometric applications using feldspar IRSL50. This first-step investigation of the feldspar athermal stability would ultimately be combined with the experimental characterisation of each sample's thermal stability (Guralnik et al., 2015a; King et al., 2016), which can vary greatly between K- and Na/Ca-feldspars (e.g. Tso et al., 1996; Li et al., 1997) and thus significantly influence thermochronometric interpretation.

Our sampling strategy, covering a wide range of exhumation rates (from 0.01 to $3 \mathrm{~km} \mathrm{Ma}^{-1}$ ), provides further information regarding the range of applicability of feldspar IRSL50 to OSL thermochronometry in diverse natural settings. All GRA and SOG samples appear in field saturation (Figure 4), with just one outlier per locality (GRA-BR and SOG-17). SOG-17 was a translucent bedrock sample, which may immediately be suspected of suffering optical resetting (in nature and/or during sample preparation), that may have biased the observed luminescence signal to below the predicted field saturation level. GRA-BR is a spatial outlier within the GRA dataset, situated at low-elevation within a very wide and deeply-carved valley. Pending additional experimental confirmation (beyond the scope of this study), its deviation from field saturation could potentially reflect recent accelerated exhumation by efficient glacial processes. Finally, more than half of the YAK samples exhibit a thermal signature in their measured natural IRSL50 signal (Table 3 and Figure 4). Samples YAK-17/-18/-50 (all with a "thermal signature") are located along a deeply-carved fjord with very high long-term exhumation rates (2-3 $\mathrm{km} \mathrm{Ma}^{-1}$; Enkelmann et al., 2015). Interestingly, the field-saturated YAK-09/-13/-15/-19 also belong to this area but are located $\sim 20 \mathrm{~km}$ eastwards along another smaller fjord (Enkelmann et al., 2015). These spatial differences in IRSL50 intensities would suggest spatial variations in the late-Quaternary exhumation history of this area that were not detected by higher-temperature thermochronometers (McAleer et al., 2009; Enkelmann et al., 2015) but 
may be evidenced in our dataset. Finally, YAK-03/-07 exhibit exceptionally low natural trap filling levels (Figure 4), which may have been caused by hydrothermal reheating from crustal fluid circulations in a highly-fractured area (Fairweather Fault; McAleer et al., 2009), rather than by extremely rapid bedrock cooling. Further work beyond the scope of the present study will focus on constraining thermal kinetic parameters for these samples to derive their thermal histories.

In summary, our dataset confirms that feldspar IRSL50 would be applicable only in very rapidly-exhuming settings (>1 $\mathrm{km} \mathrm{Ma}^{-1}$; e.g. King et al., 2016) or in high-temperature environments such as boreholes or tunnels $\left(>35{ }^{\circ} \mathrm{C}\right.$; Guralnik et al., 2015a). Feldspar anomalous fading, even if correctly accounted for, ultimately reduces the trapped charge capacity in a given crystal because of athermal instability, and thus initiates a faster arrival at field saturation. This might preclude the applicability of feldspar IRSL50 in OSL thermochronometry. MET-pIRIR protocols ( $\mathrm{Li}$ and $\mathrm{Li}, 2011 \mathrm{a}, \mathrm{b}$ ) offer the advantage of multithermochronometric systems in a single mineral (Qin et al., 2015), with promising outcomes in providing robust constraints on bedrock cooling rates over sub-Quaternary timescales (King et al., 2016). Other feldspar protocols such as thermally-transferred IRSL (Reimann et al., 2015) or pulsed IRSL50 (although the thermal stability of pulsed IRSL50 remains to be experimentally constrained; Tsukamoto et al., 2006; Roskosch et al., 2015; Jain et al., 2015b) may also be interesting to explore for thermochronometric application, providing that these protocols show good luminescence characteristics as well as low thermal stability for bedrock feldspar extracts. Alternatively, quartz protocols based on thermally-transferred OSL (Duller and Wintle, 2012), Violet Stimulated Luminescence (VSL, Ankjærgaard et al., 2013; 2015) or (red)thermoluminescence (TL or red TL, Schmidt et al., 2015; Tang and Li, 2015) could allow for later saturation and thus a wider dating range in thermochronometry.

\section{Conclusions}

We report feldspar IRSL50 luminescence characteristics, natural signal and anomalous fading for 32 bedrock samples collected from a large variety of lithologies and exhumation settings. Our results show that feldspar IRSL 50 signals from bedrock extracts are bright and reproducible using established protocols in OSL dating. We measured a large variability in IRSL50 fading rates between samples. Our results show that it is essential to measure anomalous fading and account for it on a sample-to-sample basis for OSL thermochronometry, as it may otherwise obscure any thermochronometric information. Furthermore, we exploited 
the wide range of observed fading rates to demonstrate the ability of electron tunnelling models in quantitatively predicting the feldspar IRSL 50 level in field saturation for rather diverse environmental conditions. While the potential causes for feldspar IRSL 50 $_{0}$ fading still require further investigation, our observations point towards a significant influence of Ca content in feldspar on its anomalous fading rate. Finally, our results suggest that the applicability of feldspar IRSL50 in OSL thermochronometry would be limited to rapidly-exhuming settings (i.e. $>1 \mathrm{~km} \mathrm{Ma}^{-1}$ ) or warm subsurface environments (i.e. $>35^{\circ} \mathrm{C}$ ).

\section{Acknowledgments}

We thank S. Tsukamoto and S.-H. Li for constructive and helpful reviews, A.S. Murray and M. Jain (Nordic Laboratory for Luminescence dating / DTU Ris $\varnothing$ ) for hosting an early pilot study in 2010, M. Kook for XRF measurements, and G. King and D. Sanderson for fruitful discussions and feedback. P.G.V. acknowledges funding from the SNSF (grant Ambizione PZ00P2_148191) and the ETH-Zürich COFUND. S.E.L. receives funding from the National Cooperative for the Disposal of Radioactive Waste (Nagra). F.H. and B.G. were funded through SNSF grants PP00P2-38956 and 200021-127127. B.G. acknowledges support from the NWO VENI grant 863.15.026. P.S. acknowledges the financial and scientific support from R.S. Huismans, the Statoil Earth System Modelling project and the University of Bergen.

\section{References}

Aitken, M.J., 1985. Thermoluminescence Dating. Academic Press, London. 359 pp.

Aitken, M.J., Xie, J., 1990. Moisture correction for annual gamma dose. Ancient TL 8, 6-9.

Aitken, M.J., 1998. An Introduction to Optical Dating: The Dating of Quaternary Sediments by the Use of Photon-Stimulated Luminescence. Oxford University Press. 267 pp.

Ankjærgaard, C., Jain, M., Wallinga, J., 2013. Towards dating quaternary sediments using the quartz violet stimulated luminescence (VSL) signal. Quaternary Geochronology 18, 99-109.

Ankjærgaard, C., Guralnik, B., Porat, N., Heimann, A., Jain, M., Wallinga, J., 2015. Violet stimulated luminescence: geo-or thermochronometer? Radiation Measurements 81, 78-84.

Auclair, M., Lamothe, M., Huot, S., 2003. Measurement of anomalous fading for feldspar IRSL using SAR. Radiation Measurements 37, 487-492.

Balescu, S., Lamothe, M., 1994. Comparison of TL and IRSL age estimates of feldspar coarse grains from waterlain sediments. Quaternary Science Reviews 13, 437-444.

Barré, M., Lamothe, M., 2010. Luminescence dating of archaeosediments: A comparison of Kfeldspar and plagioclase IRSL ages. Quaternary Geochronology 5, 324-328. 
Bateman, M., Swift, D.A., Piotrowski, J.A., Sanderson, D.C.W., 2012. Investigating the effects of glacial shearing of sediment on luminescence. Quaternary Geochronology 10, 230-236.

Bell, W.T., 1980. Alpha dose attenuation in quartz grains for thermoluminescence dating. Ancient TL 12, 4-8.

Berger, A.L., Spotila, J.A., Chapman, J.B., Pavlis, T.L., Enkelmann, E., Ruppert, N.A., Buscher, J.T., 2008. Architecture, kinematics, and exhumation of a convergent orogenic wedge: A thermochronological investigation of tectonic-climatic interactions within the central St. Elias Orogen, Alaska. Earth and Planetary Science Letters 270, 13-24.

Bøtter-Jensen, L., Thomsen, K.J., Jain, M., 2010. Review of optically stimulated lumi-nescence (OSL) instrumental developments for retrospective dosimetry. Radiation Measurements 45, 253-257.

Braun, J., van der Beek, P., Batt, G., 2006. Quantitative thermochronology: numerical methods for the interpretation of thermochronological data. Cambridge University Press. 258 pp.

Braun, J., van der Beek, P., Valla, P.G., Robert, X., Herman, F., 2012. Quantifying rates of landscape evolution and tectonic processes by thermochronology and numerical modelling of crustal heat transport using PECUBE. Tectonophysics 20, 1-28.

Brennan, B.J., Lyons, R.G., Phillips, S.W., 1991. Attenuation of alpha particle track dose for spherical grains. International Journal of Radiation Applications and Instrumentation. Part D. Nuclear Tracks and Radiation Measurements 18, 249-253.

Buylaert, J.P., Murray, A.S., Thomsen, K.J., Jain, M., 2009. Testing the potential of an elevated temperature IRSL signal from K-feldspar. Radiation Measurements 44, 560-565.

Buylaert, J.P., Huot, S., Murray, A.S., van den Haute, P., 2011. Infrared stimulated luminescence dating of an Eemian (MIS 5e) site in Denmark using K-feldspar. Boreas 40, 46-56.

Buylaert, J.-P., Jain, M., Murray, A.S., Thomsen, K.J., Thiel, C., Sohbati, R., 2012. A robust feldspar luminescence dating method for Middle and Late Pleistocene sediments. Boreas 41, 435-451.

Buylaert, J.P., Jain, M., Murray, A.S., Thomsen, K.J., Thiel, C., Sohbati, R., 2012. A robust feldspar luminescence dating method for Middle and Late Pleistocene sediments. Boreas 41, $435-451$.

Champagnac, J.-D., Valla, P.G., Herman, F., 2014. Late-Cenozoic relief evolution under evolving climate: A review. Tectonophysics 614, 44-65. 
De Sarkar, S., Mathew, G., Pande, K., Chauhan, N., Singhvi, A., 2013. Rapid denudation of Higher Himalaya during late Pliestocence, evidence from OSL thermochronology. Geochronometria 40, 304-310.

Duller, G.A.T., 1992. Luminescence chronology of raised marine terraces, south-west North Island, New Zealand. PhD thesis, University of Wales, Aberystwyth. 236 pp.

Duller, G.A.T., Wintle, A.G., 2012. A review of the thermally transferred optically stimulated luminescence signal from quartz for dating sediments. Quaternary Geochronology 7, 6-20.

Enkelmann, E., Valla, P.G., Champagnac, J.-D., 2015. Low-temperature thermochronology of the Yakutat Plate corner, St. Elias Range (Alaska): bridging short-term and long-term deformation. Quaternary Science Reviews 123, 23-38.

Grün, R., 2001. Trapped charge dating (ESR, TL, OSL). In: Brothwell, D.R., Pollard, A.M. (Eds.), Handbook of Archaeological Sciences. John Wiley \& Sons Inc., West Sussex, England, pp. 47-62.

Grün, R., Tani, A., Gurbanov, A., Koshchug, D., Williams, I., Braun, J., 1999. A new method for the estimation of cooling and rates using paramagnetic centers in quartz: a case study on the Eldzhurtinskiy Granite, Caucasus. Journal of Geophysical Research 104, 17531-17549.

Guérin, G., Mercier, N., 2012. Preliminary insight into dose deposition processes in sedimentary media on a grain scale : Monte Carlo modelling of the effect of water on gamma dose-rates. Radiation Measurements, 47, 541-547.

Guérin, G., Mercier, N., Nathan, R., Adamiec, G., Lefrais, Y., 2012. On the use of the infinite matrix assumption and associated concepts: a critical review. Radiation Measurements 47, 778-785.

Guralnik, B., Jain, M., Herman, F., Paris, R.B., Harrison, T.M., Murray, A.S., Valla, P.V., Rhodes, E.J., 2013. Effective closure temperature in leaky and/or saturating thermochronometers. Earth and Planetary Science Letters 384, 209-218.

Guralnik, B., Jain, M., Herman, F., Ankjærgaard, C., Murray, A.S., Valla, P.G., Preusser, F., King, G.E., Chen, R., Lowick, S.E., Kook, M., Rhodes, E.J., 2015a. OSL-thermochronology of feldspar from the KTB Borehole, Germany. Earth and Planetary Science Letters 423, 232-243.

Guralnik, B., Ankjærgaard, C., Jain, M., Murray, A.S., Müller, A., Wälle, M., Lowick, S.E., Preusser, F., Rhodes, E.J., Wu, T.-S., Mathew, G., Herman, F., 2015b. OSLthermochronometry using bedrock quartz: a note of caution. Quaternary Geochronology 25, 37-48. 
Guralnik, B., Li, B., Jain, M., Chen, R., Paris, R.B., Murray, A., Li, S.H., Pagonis, V., Valla, P.G., Herman, F., 2015c. Radiation-induced growth and isothermal decay of infraredstimulated luminescene from feldspar. Radiation Measurements 81, 224-231.

Hendriks, B., Andriessen, P., Huigen, Y., Leighton, C., Redfield, T., Murrell, G., Gallagher, K., Nielsen, S.B., 2007. A fission track data compilation for Fennoscandia. Norwegian Journal of Geology 87, 143-155.

Herman, F., Champagnac, J.-D., 2016. Plio-Pleistocene increase in erosion rates in mountain belts in response to climate change. Terra Nova 28, 2-10.

Herman, F., Rhodes, E.J., Braun, J., Heiniger, L., 2010. Uniform erosion rates and re-lief amplitude during glacial cycles in the Southern Alps of New Zealand, as revealed from OSL-thermochronology. Earth and Planetary Science Letters 297, 183-189.

Herman, F., Seward, D., Valla, P.G., Carter, A., Kohn, B., Willett, S.D., Ehlers, T.A., 2013. Worldwide acceleration of mountain erosion under a cooling climate. Nature 504, 423-426.

Hijmans, R.J., Cameron, S.E., Parra, J.L., Jones, P.G., Jarvis, A., 2005. Very high resolution interpolated climate surfaces for global land areas. International Journal of Climatology 25, 1965-1978.

Huntley, D.J., Hutton, J.T., Prescott, J.R., 1993. Optical dating using inclusions within quartz grains. Geology 21, 1087-1090.

Huntley, D.J., Baril, M.R., 1997. The K content of the K-feldspars being measured in optical dating or in thermoluminescence dating. Ancient TL 15, 11-13.

Huntley, D.J., Lamothe, M., 2001. Ubiquity of anomalous fading in K-feldspars and the measurement and correction for it in optical dating. Canadian Journal of Earth Sciences 38, 1093-1106.

Huntley, D.J., 2006. An explanation of the power-law decay of luminescence. Journal of Physics: Condensed Matter 18, 1359-1365.

Huntley, D.J., Lian, O.B., 2006. Some observations on tunnelling of trapped electrons in feldspars and their implications for optical dating. Quaternary Science Reviews 25, 25032512.

Huntley, D.J., Baril, M.R., Haidar, S., 2007. Tunnelling in plagioclase feldspars. Journal of Physics D: Applied Physics 40, 900-906.

Huntley, D.J., 2011. Comment on "Isochron dating of sediments using luminescence of Kfeldspar grains” by B. Li et al. Journal of Geophysical Research 116, F01012. 
Jain, M., Guralnik, B., Andersen, M.T., 2012. Stimulated luminescence emission arising from localized recombination within randomly distributed defects. Journal of Physics Condensed Matter 24, 385402.

Jain, M., Sohbati, R., Guralnik, B., Murray, A.S., Kook, M., Lapp, T., Prasad, A.K., Thomsen, K.J., Buylaert, J.P, 2015a. Kinetics of infrared stimulated luminescence from feldspars. Radiation Measurements 81, 242-250.

Jain, M., Buylaert, J.P., Thomsen, K.J., Murray, A.S., 2015b. Further investigations on 'nonfading' in K-Feldspar. Quaternary International 362, 3-7.

Kars, R.H., Wallinga, J., Cohen, K.M., 2008. A new approach towards anomalous fading correction for feldspar IRSL dating - tests on samples in field saturation. Radiation Measurements 43, 786-790.

Kars, R.H., Wallinga, J., 2009. IRSL dating of K-feldspars: Modelling natural dose response curves to deal with anomalous fading and trap competition. Radiation Measurements 44, 594-599.

Kars, R.H., Reimann, T., Wallinga, J., 2014. Are feldspar SAR protocols appropriate for postIR IRSL dating? Quaternary Geochronology 22, 126-136.

King, G.E., Herman, F., Lambert, R., Valla, P.G., Guralnik, B., 2016. Multi-OSLthermochronometry of feldspar. Quaternary Geochronology 33, 76-87

King, G.E., Robinson, R.A.J., Finch, A.A., 2014. Towards successful OSL sampling strategies in glacial environments: deciphering the residual OSL signals of quartz and K-feldspar from modern glacial sediments. Quaternary Science Reviews 89, 94-107.

Kook, M.H., Lapp, T., Murray, A.S., Thiel, C., 2012. A Ris $\varnothing$ XRF attachment for major element analysis of aliquots of quartz and feldspar separates. UK Luminescence and ESR Meeting - Aberystwyth, p. 37.

Koshchug, D.G., Solovyov, Y.P., 1998. Accumulation of structural radiation defects in quartz in cooling systems: Basis for dating. Physics and Chemistry of Minerals 25, 242-248.

Lamothe, M., Auclair, M., 1999. A solution to anomalous fading and age shortfalls in optical dating of feldspar minerals. Earth and Planetary Science Letters 171, 319-323.

Lamothe, M., Auclair, M., Hamzaoui, C., Huot, S., 2003. Towards a prediction of long-term anomalous fading of feldspar IRSL. Radiation Measurements 37, 493-498.

Li, S-H., Tso, M-Y.W., Wong, N.W.L., 1997. Parameters of OSL traps determined with various linear heating rates. Radiation Measurements 27, 43-47.

Li, B., Li, S.-H., 2006. Comparison of De estimates using the fast component and the medium component of quartz OSL. Radiation Measurements 41, 125-136. 
Li, B., Li, S.-H., 2008. Investigations of the dose-dependent anomalous fading rate of feldspar from sediments. Journal of Physics D: Applied Physics 41, 225502.

Li, B., Li, S.-H., 2011a. Luminescence dating of K-feldspar from sediments: a protocol without anomalous fading correction. Quaternary Geochronology 6, 468-479.

Li, B., Li, S.-H., 2011b. Thermal stability of infrared stimulated luminescence of sedimentary K-feldspar. Radiation Measurements 46, 29-36.

Li, B., Li, S.-H., 2012. Determining the cooling age using luminescence-thermochronology. Tectonophysics 580, 242-248.

Li, B., Jacobs, Z., Roberts, R.G., Li, S.H., 2014. Review and assessment of the potential of post-IR IRSL dating methods to circumvent the problem of anomalous fading in feldspar luminescence. Geochronometria 41, 178-201.

McAleer, R.J., Spotila, J.A., Enkelmann, E., Berger, A.L., 2009. Exhumation along the Fairweather Fault, Southeast Alaska, based on Low-Temperature thermochronometry. Tectonics 28, TC1007.

Nielsen, S.B., Gallagher, K., Leigton, C., Balling, N., Svenningsen, L., Jacobsen, B.H., Thomsen, E., Nielsen, O.B., Heilmann-Clausen, C., Egholm, D.L., Summerfield, M.A., Clausen, O.R., Piotrowski, J.A., Thorsen, M.R., Huuse, M., Abrahamsen, N., King, C., Lykke-Andersen, H., 2009. The evolution of western Scandinavian topography: a review of Neogene uplift versus the ICE (isostasy-climate-erosion) hypothesis. Journal of Geodynamics 47, 72-95.

Parish, R., 1992. The application of sedimentological analysis and luminescence dating to waterlain deposits from archaeological sites. PhD Thesis, Durham University, 263 pp.

Preusser, F., Chithambo, M.L., Götte, T., Martini, M., Ramseyer, K., Sendezera, E.J., Susino, G.J., Wintle, A.G., 2009. Quartz as a natural luminescence dosimeter. Earth Science Reviews 97, 184-214.

Prokein, J., Wagner, G.A., 1994. Analysis of thermoluminescent glow peaks in quartz derived from the KTB-drill hole. Radiation Measurements 23, 85-94.

Qin, J., Chen, J., Valla, P.G., Herman, F., Li, K., 2015. Estimating rock cooling rates by using multiple luminescence thermochronometers. Radiation Measurements 79, 13-18.

Reimann, T., Ankjærgaard, C., Wallinga, J., 2015. Testing the potential of a transferred IRSL (T-IRSL) feldspar signal for luminescence dating. Radiation Measurements 81, 275-281.

Reiners, P.W., Brandon, M.T., 2006. Using thermochronology to understand orogenic erosion. Annual Review of Earth and Planetary Sciences 34, 419-466. 
Rhodes, E.J., 2011. Optically stimulated luminescence dating of sediments over the past 200,000 years. Annual Review of Earth and Planetary Sciences 39, 461-488.

Roskosch, J., Winsemann, J., Polom, U., Brandes, C., Tsukamoto, S., Weitkamp, A., Bartholomäus, W.A., Henningsen, D., Frechen, M., 2015. Luminescence dating of icemarginal deposits in northern Germany: evidence for repeated glaciations during the Middle Pleistocene (MIS 12 to MIS 6). Boreas 44, 103-126.

Schmidt, C., Friedrich, J., Zöller, L., 2015. Thermochronometry using red TL of quartz? e Numerical simulation and observations from in-situ drill-hole samples. Radiation Measurements 81, 98-103.

Shuster, D.L., Farley, K.A., 2005. ${ }^{4} \mathrm{He} /{ }^{3} \mathrm{He}$ Thermochronometry: Theory, Practice, and Potential Complications. Reviews in Mineralogy and Geochemistry 58, 181-203.

Shuster, D.L., Ehlers, T.A., Rusmore, M.E., Farley, K.A., 2005. Rapid glacial erosion at 1.8 Ma revealed by ${ }^{4} \mathrm{He} /{ }^{3} \mathrm{He}$ thermochronometr. Science $310,1668-1670$.

Shuster, D.L., Cuffey, K.M., Sanders, J.W., Balco, G., 2011. Thermochronometry Reveals Headward Propagation of Erosion in an Alpine Landscape. Science 332, 84-88.

Sohbati, R., Murray, A., Jain, M., Thomsen, K., Hong, S.C., Yi, K., Choi, J.H., 2013. Na-rich feldspar as a luminescence dosimeter in infrared stimulated luminescence (IRSL) dating. Radiation Measurements 51-52, 67-82.

Spooner, N.A., 1994. The anomalous fading of infra-red stimulated luminescence from feldspars. Radiation Measurements 23, 625-632.

Spotila, J.A., Buscher, J.T., Meigs, A.J., Reiners, P.W., 2004. Long-term glacial erosion of active mountain belts: Example of the Chugach-St. Elias Range, Alaska. Geology 32, 501504.

Steer, P., Huismans, R.S., Valla, P.G., Gac, S., Herman, F., 2012. Bimodal Plio-Quaternary glacial erosion of fjords and low-relief surfaces in Scandinavia. Nature Geoscience 5, 635639.

Tang, S.L., Li, S.-H., 2015. Low temperature thermochronology using thermoluminescence signals from quartz. Radiation Measurements 81, 92-97.

Thomsen, K.J., Murray, A.S., Jain, M., Bøtter-Jensen, L., 2008. Laboratory fading rates of various luminescence signals from feldspar-rich sediment extracts. Radiation Measurements 43, 1474-1486.

Thomsen, K., Murray, A., Jain, M., 2011. Stability of IRSL signals from sedimentary Kfeldspar samples. Geochronometria 38, 1-13. 
Tso, M-Y.W., Wong, N.W.L., Li, S-H., 1996. Determination of life time of infrared stimulated signals from potassium and sodium feldspars. Radiation Protection Dosimetry 66, 387-389.

Tsukamoto, S., Denby, P.M., Murray, A.S., Bøtter-Jensen, L., 2006. Time-resolved luminescence from feldspars: New insight into fading. Radiation Measurements 41, 790795.

Valla, P.G., Shuster, D.L., van der Beek, P.A., 2011a. Significant increase in relief of the European Alps during Mid-Pleistocene glaciations. Nature Geoscience 4, 688-692.

Valla, P.G., van der Beek, P.A., Braun, J., 2011b. Rethinking low-temperature thermochronology data sampling strategies for quantification of denudation and relief histories: a case study in the French western Alps. Earth and Planetary Science Letters 307, 309-322.

Visocekas, R., 2002. Tunneling in afterglow, its coexistence and interweaving with thermally stimulated luminescence. Radiation Protection Dosimetry 100, 45-54.

Wagner, G.A., Reimer, G.M., 1972. Fission track tectonics: the tectonic interpretation of fission track apatite ages. Earth and Planetary Science Letters 14, 263-268.

Wallinga, J., Murray, A.S., Wintle, A., 2000. The single-aliquot regenerative-dose (SAR) protocol applied to coarse-grain feldspar. Radiation Measurements 32, 529-533.

Willenbring, J.K., Jerolmack, D.J., 2016. The null hypothesis: globally steady rates of erosion, weathering fluxes and shelf sediment accumulation during Late Cenozoic mountain uplift and glaciation. Terra Nova 28, 11-18.

Wintle, A.G., Murray, A.S., 2006. A review of quartz optically stimulated luminescence characteristics and their relevance in single-aliquot regeneration dating protocols. Radiation Measurements 41, 369-391.

Wintle, A.G., 2008. Luminescence dating: where it has been and where it is going. Boreas 37, 471-482.

Wu, T.S., Kunz, A., Jaiswal, M.K., Chen, Y.G., 2012. A feasibility study on the application of luminescence dating for quartz from different rock types as a thermochronometer. Quaternary Geochronology 10, 340-344.

Wu, T.-S., Jain, M., Guralnik, B., Murray, A.S., Chen, Y.-G., 2015. Luminescence characteristics of quartz from Hsuchshan Range (Central Taiwan) and the implications as a thermochronometer. Radiation Measurements 81, 104-109.

Yi, S., Buylaert, J.-P., Murray, A.S., Lu, H., Thiel, C., Zeng, L., in press. A detailed post-IR IRSL study of the Niuyangzigou loess site in northeastern China. Boreas. 


\section{Figure captions}

Figure 1. IRSL 50 dose-response curves (left panels) and fading experiments (central and right panels) for representative samples GRA-08 (A-B-C), GRA-12 (D-E-F), SOG-06 (G-H-I) and YAK-09 (J-K-L). See Tables 2 and 3 for experimental details and results, respectively. The dose-response curves (left panels) have been obtained following the single aliquot regenerative-dose (SAR) protocol for 3 individual aliquots. The natural luminescence signal (white stars) and each regenerative dose (black circles) are normalised to a given test dose, and used to build the dose-response curve (fitted by the GOK approach, black line and grey envelope; $\alpha$ : electron-trapping order, $\mathrm{D}_{0}$ : characteristic dose) and to calculate the sample natural luminescence level $\left(\mathrm{L}_{n} / \mathrm{T}_{\mathrm{n}}\right)$ and natural trap filling $(\mathrm{n} / \mathrm{N})_{\text {nat }}($ Guralnik et al., 2015a). Fading experiments, following the long-shine (central panels) and short-shine (right panels) protocols, were used to derive the sample fading rate (sample-specific $\mathrm{g}_{2 \text { days }}$ are given by the slope of the black lines normalized to 2 days; Huntley and Lamothe, 2001).

Figure 2. Comparison of fading rate measurements ( $\left.\mathrm{g}_{2 \mathrm{days}}\right) \mathrm{using}$ the short-shine and long-shine methods (Table 3). The symbols represent individual GRA (black circles), YAK (grey squares) and SOG (open triangles) samples. The dashed line defines the 1:1 relationship. The inset shows a zoom-in to the low-fading rate region (dashed box in main panel).

Figure 3. Natural trap filling $(\mathrm{n} / \mathrm{N})_{\text {nat }}$ and $\mathrm{g}_{2 \text { days }}$ values (long-shine method, Table 3 ) for GRA (black circles), YAK (grey squares) and SOG (open triangles) samples. Samples in field saturation define a well-characterised inverse relationship between laboratory-measured fading rates $\left(\mathrm{g}_{2 \text { days }}\right)$ and the natural trap filling $(\mathrm{n} / \mathrm{N})_{\text {nat }}$ values over a wide range of fading rates (from $\sim 0.5$ to $\sim 45 \% /$ decade).

Figure 4. Predicted field saturation $(n / N)_{s s}$ vs. measured natural trap filling $(n / N)_{\text {nat }}$ for GRA (circles), YAK (squares) and SOG (triangles) samples (A: lineal plot; B: logarithmic plot). Symbols are coloured according to the individual sample $\mathrm{g}_{2 \mathrm{days}}$ values (see legend). Most of analysed samples plot along the 1:1 relationship (dashed line), validating the approach of Guralnik et al. (2015a) to numerically predict sample field saturation (after Huntley, 2006 and Kars et al., 2008). Some samples have $(\mathrm{n} / \mathrm{N})_{\text {nat }}$ below $0.85(\mathrm{n} / \mathrm{N})_{\mathrm{ss}}$ (dotted line), bearing potential thermochronometric information. See text for details and discussion. 
Figure 5. Feldspar geochemistry and laboratory-measured fading rate. (A) Whole-rock representative oxides showing the lithological variability between analysed samples (Supplementary Table S2). (B) Feldspar mineralogical compositions for a subset of samples (Ab: albite; An: anorthite; Or: orthoclase; Supplementary Table S4). GRA: circles; YAK: squares; SOG: triangles. Symbols are coloured according to the respective sample's $\mathrm{g}_{2 \mathrm{days}}$ value (see legend). See text for discussion. 
Table 1. Overview of sample locations, lithology and climate, alongside measured radionuclides and calculated natural dose rate.

\begin{tabular}{|c|c|c|c|c|c|c|c|}
\hline \multirow[t]{2}{*}{ Sample } & \multirow{2}{*}{$\begin{array}{l}\text { Latitude/ } \\
\text { Longitude } \\
\left({ }^{\circ} \mathrm{N}\right) /\left({ }^{\circ} \mathrm{W}\right)\end{array}$} & \multirow{2}{*}{$\begin{array}{c}\text { Elevation } \\
(\mathrm{m})\end{array}$} & \multirow[t]{2}{*}{ Lithology } & \multirow{2}{*}{$\begin{array}{l}\text { Mean Annual } \\
\text { Temperature } \\
\left({ }^{\circ} \mathrm{C}\right)\end{array}$} & \multicolumn{3}{|c|}{ Whole-rock geochemistry ${ }^{2}$} \\
\hline & & & & & $\mathrm{U}(\mathrm{ppm})$ & Th (ppm) & $\mathrm{K}(\mathrm{wt} . \%)$ \\
\hline \multicolumn{8}{|c|}{ Granite Range ( southern Alaska) } \\
\hline GRA-03 & $60.853 / 141.451$ & 1419 & Diorite & -5.8 & 0.4 & 1.1 & 0.79 \\
\hline GRA-04 & $60.832 / 141.467$ & 1761 & Diorite & -4.5 & 0.2 & 0.6 & 0.82 \\
\hline GRA-05 & $60.835 / 141.469$ & 1995 & Diorite & -6.3 & 0.4 & 1.1 & 0.86 \\
\hline GRA-06 & $60.841 / 141.501$ & 2388 & Diorite & -6.8 & 0.3 & 0.5 & 0.76 \\
\hline GRA-08 & $60.905 / 141.970$ & 2188 & Diorite & -7.3 & 0.3 & 0.8 & 0.97 \\
\hline GRA-09 & $60.901 / 141.954$ & 1691 & Diorite & -5.7 & 0.1 & 0.1 & 0.50 \\
\hline GRA-10 & $60.900 / 141.934$ & 1412 & Diorite & -4.2 & 0.3 & 1.1 & 2.02 \\
\hline GRA-11 & $60.908 / 141.919$ & 970 & Diorite & -3 & 0.6 & 1.1 & 0.81 \\
\hline GRA-12 & $60.991 / 142.763$ & 1554 & Schist & -2.5 & 0.3 & 0.5 & 1.03 \\
\hline GRA-13 & $61.003 / 142.741$ & 1253 & Granitoïde & -1.5 & 1.2 & 9.4 & 0.72 \\
\hline GRA-14 & $60.991 / 142.782$ & 1979 & Granitoïde & -4.2 & 0.9 & 1.3 & 1.09 \\
\hline GRA-17 & $60.943 / 142.475$ & 1818 & Granitoïde & -6.1 & 0.3 & 0.5 & 0.61 \\
\hline GRA-18 & $60.957 / 142.378$ & 1395 & Schist & -4.1 & 0.1 & 0.3 & 0.61 \\
\hline GRA-19 & $61.008 / 142.362$ & 720 & Granitoïde & -1.4 & 1.6 & 3.6 & 0.73 \\
\hline GRA-BR & $61.109 / 142.420$ & 392 & Monzogranite & -0.2 & 1.6 & 3.9 & 2.17 \\
\hline \multicolumn{8}{|c|}{ Sognefjord (western Norway) } \\
\hline SOG-02 & 61.096/-5.681 & 33 & Granitic gneiss & 7.4 & 1.8 & 10.4 & 4.18 \\
\hline SOG-06 & $61.155 /-6.461$ & 883 & Granitic gneiss & 2.4 & 2.2 & 8.3 & 5.13 \\
\hline SOG-10 & $61.146 /-6.542$ & 47 & Granitic gneiss & 6.5 & 1.1 & 10.3 & 4.76 \\
\hline SOG-17 & $61.233 /-7.593$ & 961 & Granodiorite & 1.1 & 0.2 & 0.2 & 4.13 \\
\hline SOG-21 & $61.239 /-7.664$ & 10 & Anorthosite & 3.5 & 0.7 & 10.5 & 5.15 \\
\hline SOG-22 & $61.263 /-7.867$ & 1274 & Gabbro & -0.9 & 0.1 & 0.8 & 0.52 \\
\hline SOG-25 & $61.272 /-7.765$ & 48 & Anorthosite & 4.8 & 0.6 & 5.5 & 5.30 \\
\hline SOG-38 & $61.151 /-6.728$ & 21 & Granitic gneiss & 7.0 & 0.4 & 3.7 & 5.13 \\
\hline \multicolumn{8}{|c|}{ Yakutat terrane (southern Alaska) } \\
\hline YAK-03 & $59.813 / 138.912$ & 5 & Diorite & 0.3 & 0.1 & 0.3 & 0.18 \\
\hline YAK-07 & $59.843 / 139.162$ & 2 & Diorite & 1.6 & 0.1 & 0.1 & 0.04 \\
\hline YAK-09 & $59.825 / 138.986$ & 0 & Diorite & 2.3 & 2.5 & 4.4 & 1.72 \\
\hline YAK-13 & $59.647 / 139.296$ & 2 & Sandstone & 3.5 & 1.7 & 6.3 & 1.37 \\
\hline YAK-15 & $59.851 / 139.313$ & 1 & Sandstone & 3.0 & 2 & 4.8 & 1.53 \\
\hline YAK-17 & $59.974 / 139.450$ & 2 & Sandstone & 2.2 & 1.4 & 3.9 & 0.62 \\
\hline YAK-18 & $59.967 / 139.531$ & 1 & Sandstone & 2.9 & 1.2 & 3.5 & 1.87 \\
\hline YAK-19 & $59.597 / 139.342$ & 2 & Sandstone & 3.2 & 1.6 & 3.2 & 1.89 \\
\hline YAK-50 & $59.946 / 139.620$ & 0 & Sandstone & 2.6 & 1.2 & 3.5 & 1.11 \\
\hline
\end{tabular}

Notes. ${ }^{1}$ Derived from Worldclim database (Hijmans et al., 2005). ${ }^{2}$ Measured on a Perkin Elmer Sciex ELAN 6100/9000 ICP-MS, with an estimated analytical precision of $2.3(\mathrm{U}), 3.4 \%$ (Th) and $1.2 \%(\mathrm{~K})$. See Supplementary Tables S2-S3 for all elements and further details. ${ }^{3}$ Measured or estimated as follows: ${ }^{a}$ measured using the Ris $\varnothing$ XRF attachment (Kook et al., 2012); ${ }^{b}$ assumed value for $\mathrm{Na} / \mathrm{Ca}$-feldspars (average of the Ris $\varnothing \mathrm{XRF}$ data above) ${ }^{\mathrm{c}}$ assumed value for $\mathrm{K}$-feldspars (Huntley and Baril, 1997; Barré and Lamothe, 2010) ${ }^{4}$ For calculation of feldspar dose rates, we used conversion factors of Guérin et al. (2012), water content of $2( \pm 2) \%$, and negligible cosmic 
radiation. The reported dose rates cover two (or four) end-member scenarios after Guralnik et al. 2015a (see Table S1). For K-feldspars, two end-member grain sizes were considered (180 and 1000 or $2500 \mu \mathrm{m})$; for $\mathrm{Na} / \mathrm{Ca}$-feldspars, two additional scenarios, in which the entire luminescence signal originates from K-feldspar inclusions $(1$ or $100 \mu \mathrm{m})$ were further included (Table S1). 
Table 2. Laboratory protocols for luminescence measurements of feldspar IRSL50.

\begin{tabular}{|c|c|c|}
\hline \multirow{2}{*}{$\begin{array}{l}\text { Dose response } \\
\text { SAR protocol }^{\mathrm{a}}\end{array}$} & \multicolumn{2}{|c|}{ Anomalous fading } \\
\hline & SAR protocol, (Long-shine method $\left.{ }^{b}\right)$ & Short-shine method ${ }^{c}$ \\
\hline & 1. IRSL at $290^{\circ} \mathrm{C}(200 \mathrm{~s})$ & 1. IRSL at $290^{\circ} \mathrm{C}(200 \mathrm{~s})$ \\
\hline 1. Give dose $D_{x}$ & 2. Give dose $D_{\text {fading }}$ & 2. Give dose $D_{\text {fading }}$ \\
\hline 2. Preheat $\left(250^{\circ} \mathrm{C}\right.$ for $\left.60 \mathrm{~s}\right)$ & 3. Preheat $\left(250^{\circ} \mathrm{C}\right.$ for $\left.60 \mathrm{~s}\right)$ & 3. Preheat $\left(250^{\circ} \mathrm{C}\right.$ for $\left.60 \mathrm{~s}\right)$ \\
\hline & 4. Hold at room $T^{\circ} \mathrm{C}$ for $t_{x} \mathrm{~S}$ & 4. Hold at room $T^{\circ} \mathrm{C}$ for $t_{x} \mathrm{~S}$ \\
\hline 3. IRSL at $50^{\circ} \mathrm{C}(200 \mathrm{~s}) \rightarrow L_{x}$ & 5. IRSL at $50^{\circ} \mathrm{C}(200 \mathrm{~s}) \rightarrow L_{x}$ & $\begin{array}{l}\text { 5. IRSL at } 50^{\circ} \mathrm{C}(0.1 \mathrm{~s}) \rightarrow L_{x} \\
\text { 6. Return to step } 4 \\
\text { 7. IRSL at } 290^{\circ} \mathrm{C}(200 \mathrm{~s})\end{array}$ \\
\hline 4. Give test dose $D_{\text {test }}$ & 6. Give test dose $D_{\text {test }}$ & 8. Give test dose $D_{\text {test }}$ \\
\hline 5. Preheat $\left(250^{\circ} \mathrm{C}\right.$ for $\left.60 \mathrm{~s}\right)$ & 7. Preheat $\left(250^{\circ} \mathrm{C}\right.$ for $\left.60 \mathrm{~s}\right)$ & 9. Preheat $\left(250^{\circ} \mathrm{C}\right.$ for $\left.60 \mathrm{~s}\right)$ \\
\hline $\begin{array}{l}\text { 6. IRSL at } 50^{\circ} \mathrm{C}(200 \mathrm{~s}) \rightarrow T_{x} \\
\text { 7. IRSL at } 290^{\circ} \mathrm{C}(200 \mathrm{~s})\end{array}$ & 8. IRSL at $50^{\circ} \mathrm{C}(200 \mathrm{~s}) \rightarrow T_{x}$ & 10. IRSL at $50^{\circ} \mathrm{C}(0.1 \mathrm{~s}) \rightarrow T_{x}$ \\
\hline 8. Return to step 1 & 9. Return to step 1 & 11. Return to step 10 \\
\hline
\end{tabular}

Protocols adapted from Guralnik et al. (2015a). ${ }^{a}$ The irradiation doses of the SAR dose response protocol (Wallinga et al., 2000) were $D_{x}=[0,22,44,87,175,349,698,1396,2792,0,87] \mathrm{Gy}$, and the test dose was $D_{\text {test }}=44 \mathrm{~Gy}$. The first and the penultimate zero-doses (no irradiation) extract the natural dose and signal recuperation, respectively. ${ }^{b}$ The irradiation and test doses of the long-shine fading experiment (Huntley and Lamothe, 2001) were $D_{\text {fading }}=240$ Gy and $D_{\text {test }}=44$ Gy, respectively, and the holding times were $t_{x} \approx[1200,1200,1200,136660,1200,7970,1200$, 143450, 1200, 1200 1200] s. ${ }^{c}$ The short-shine fading experiment (Auclair et al., 2003) consisted of a single irradiation dose $D_{\text {fading }}=72$ Gy which was given, followed by delay times of $t_{x} \approx 10^{2.34+0.37 x} \mathrm{~s}$, where $\mathrm{x}=[1,2, \ldots, 8]$. The test dose was $D_{\text {test }}=72$ Gy. $L_{x}$ and $T_{x}$ in both SAR protocols (left and central column) were derived by integrating the first $15 \mathrm{~s}$ of the stimulation curve (signal) after subtraction of the last $100 \mathrm{~s}$ (background). $L_{x}$ and $T_{x}$ of the short-shine experiment (right column) were derived by integrating the entire stimulation period of $0.1 \mathrm{~s}$, after subtraction of a $20 \mathrm{~ms}$ background (immediately following the IRSL stimulation). Note: All preheats were done with a linear heating rate of $5^{\circ} \mathrm{C} \mathrm{s}^{-1}$. 
Table 3. Best-fit parameters and model results for feldspar IRSL 50 .

\begin{tabular}{|c|c|c|c|c|c|c|c|c|}
\hline & \multicolumn{6}{|c|}{ Fitted kinetic parameters } & \multicolumn{2}{|c|}{ Interpretation } \\
\hline $\begin{array}{l}\text { Sampl } \\
\text { e }\end{array}$ & (Gy) & $\begin{array}{c}\text { Electron } \\
- \\
\text { trapping } \\
\text { order } \\
(\alpha)\end{array}$ & $\begin{array}{c}\text { Long- } \\
\text { shine } \\
\text { g } 2 \text { days } \\
(\% / d e c a \\
\text { de })\end{array}$ & $\begin{array}{l}\text { Long- } \\
\text { shine } \\
\log _{10} \rho^{\prime}\end{array}$ & $\begin{array}{c}\text { Short- } \\
\text { shine } \\
\text { g2days } \\
\text { (\%/deca } \\
\text { de })\end{array}$ & $\begin{array}{c}\text { Short- } \\
\text { shine } \\
\log _{10} \rho^{\prime}\end{array}$ & $\begin{array}{c}\text { Observed } \\
(\mathbf{n} / \mathbf{N})_{\text {nat }}\end{array}$ & $\begin{array}{l}\text { Predicted } \\
(\mathbf{n} / \mathbf{N})_{\mathrm{ss}}\end{array}$ \\
\hline $\begin{array}{c}\text { GRA- } \\
03\end{array}$ & $\begin{array}{l}1208 \\
( \pm 59)\end{array}$ & 4 & $\begin{array}{c}41.3 \\
( \pm 1.2)\end{array}$ & $\begin{array}{c}-4.69 \\
( \pm 0.01)\end{array}$ & $\begin{array}{c}47.7 \\
( \pm 4.5)\end{array}$ & $\begin{array}{c}-4.68 \\
( \pm 0.03)\end{array}$ & $\begin{array}{c}0.003 \\
( \pm 0.003)\end{array}$ & $0.002( \pm 0.0002)$ \\
\hline $\begin{array}{c}\text { GRA- } \\
\text { 04 }\end{array}$ & $\begin{array}{l}1208 \\
( \pm 75)\end{array}$ & 4 & $\begin{array}{c}28.5 \\
( \pm 0.7)\end{array}$ & $\begin{array}{l}-4.81 \\
( \pm 0.01)\end{array}$ & $\begin{array}{r}\text { Low sign } \\
\text { ra }\end{array}$ & $\begin{array}{l}\text { 1-to-noise } \\
\text { io }\end{array}$ & $\begin{array}{c}0.007 \\
( \pm 0.005)\end{array}$ & $0.007( \pm 0.001)$ \\
\hline $\begin{array}{l}\text { GRA- } \\
05\end{array}$ & $\begin{array}{c}550 \\
( \pm 71)\end{array}$ & $\begin{array}{c}2.56 \\
( \pm 0.82)\end{array}$ & $\begin{array}{c}28.0 \\
( \pm 1.0)\end{array}$ & $\begin{array}{c}-4.82 \\
( \pm 0.01)\end{array}$ & $\begin{array}{c}23.5 \\
( \pm 3.1)\end{array}$ & $\begin{array}{c}-4.89 \\
( \pm 0.04)\end{array}$ & $\begin{array}{c}0.017 \\
( \pm 0.003)\end{array}$ & $0.017( \pm 0.004)$ \\
\hline $\begin{array}{l}\text { GRA- } \\
\text { 06 }\end{array}$ & $\begin{array}{c}612 \\
( \pm 29)\end{array}$ & $\begin{array}{c}1.64 \\
( \pm 0.26)\end{array}$ & $\begin{array}{c}36.2 \\
( \pm 1.4)\end{array}$ & $\begin{array}{c}-4.74 \\
( \pm 0.01)\end{array}$ & $\begin{array}{c}23.3 \\
( \pm 3.2)\end{array}$ & $\begin{array}{c}-4.89 \\
( \pm 0.05)\end{array}$ & $\begin{array}{c}0.008 \\
( \pm 0.002)\end{array}$ & $0.012( \pm 0.002)$ \\
\hline $\begin{array}{l}\text { GRA- } \\
\text { 08 }\end{array}$ & $\begin{array}{c}599 \\
( \pm 31)\end{array}$ & $\begin{array}{c}1.60 \\
( \pm 0.28)\end{array}$ & $\begin{array}{c}33.8 \\
( \pm 0.8)\end{array}$ & $\begin{array}{c}-4.75 \\
( \pm 0.01)\end{array}$ & $\begin{array}{c}29.9 \\
( \pm 6.3)\end{array}$ & $\begin{array}{c}-4.82 \\
( \pm 0.07)\end{array}$ & $\begin{array}{c}0.015 \\
( \pm 0.003)\end{array}$ & $\begin{array}{c}0.009(+0.002 /- \\
0.003)\end{array}$ \\
\hline $\begin{array}{l}\text { GRA- } \\
09\end{array}$ & $\begin{array}{c}718 \\
( \pm 115)\end{array}$ & $\begin{array}{c}2.11 \\
( \pm 0.86)\end{array}$ & $\begin{array}{c}23.6 \\
( \pm 0.6)\end{array}$ & $\begin{array}{c}-4.88 \\
( \pm 0.01)\end{array}$ & $\begin{array}{c}22.2 \\
( \pm 3.2)\end{array}$ & $\begin{array}{c}-4.92 \\
( \pm 0.05)\end{array}$ & $\begin{array}{c}0.016 \\
( \pm 0.007)\end{array}$ & $0.022( \pm 0.006)$ \\
\hline $\begin{array}{l}\text { GRA- } \\
10\end{array}$ & $\begin{array}{c}519 \\
( \pm 36)\end{array}$ & $\begin{array}{c}1.67 \\
( \pm 0.38)\end{array}$ & $\begin{array}{c}12.9 \\
( \pm 0.3)\end{array}$ & $\begin{array}{c}-5.10 \\
( \pm 0.01)\end{array}$ & $\begin{array}{c}14.3 \\
( \pm 1.7)\end{array}$ & $\begin{array}{c}-5.07 \\
( \pm 0.04)\end{array}$ & $\begin{array}{c}0.120 \\
( \pm 0.027)\end{array}$ & $\begin{array}{c}0.098(+0.016 /- \\
0.012)\end{array}$ \\
\hline $\begin{array}{l}\text { GRA- } \\
11\end{array}$ & $\begin{array}{c}606 \\
( \pm 73)\end{array}$ & 4 & $\begin{array}{c}11.1 \\
( \pm 0.6)\end{array}$ & $\begin{array}{c}-5.16 \\
( \pm 0.02)\end{array}$ & $\begin{array}{r}\text { Low sign } \\
\text { ra }\end{array}$ & $\begin{array}{l}\text { l-to-noise } \\
\text { io }\end{array}$ & $\begin{array}{c}0.074 \\
( \pm 0.015)\end{array}$ & $\begin{array}{c}0.113(+0.011 /- \\
0.012)\end{array}$ \\
\hline $\begin{array}{l}\text { GRA- } \\
12\end{array}$ & $\begin{array}{c}545 \\
( \pm 10)\end{array}$ & $\begin{array}{c}2.92 \\
( \pm 0.12)\end{array}$ & $\begin{array}{c}13.9 \\
( \pm 0.3)\end{array}$ & $\begin{array}{c}-5.08 \\
( \pm 0.01)\end{array}$ & $\begin{array}{c}14.2 \\
( \pm 1.3)\end{array}$ & $\begin{array}{c}-5.07 \\
( \pm 0.03)\end{array}$ & $\begin{array}{c}0.092 \\
( \pm 0.005)\end{array}$ & $\begin{array}{c}0.074(+0.009 /- \\
0.007)\end{array}$ \\
\hline $\begin{array}{l}\text { GRA- } \\
13\end{array}$ & $\begin{array}{l}132 \\
( \pm 3)\end{array}$ & $\begin{array}{c}1.62 \\
( \pm 0.08)\end{array}$ & $\begin{array}{c}0.5 \\
( \pm 0.3)\end{array}$ & $\begin{array}{l}-6.50 \\
( \pm 0.26)\end{array}$ & $\begin{array}{r}\text { Low sign } \\
\text { ra }\end{array}$ & $\begin{array}{l}\text { l-to-noise } \\
\text { io }\end{array}$ & $\begin{array}{c}0.845 \\
( \pm 0.024)\end{array}$ & $\begin{array}{c}0.903(+0.054 /- \\
0.023)\end{array}$ \\
\hline $\begin{array}{l}\text { GRA- } \\
14\end{array}$ & $\begin{array}{l}243 \\
( \pm 4)\end{array}$ & $\begin{array}{c}1.76 \\
( \pm 0.07)\end{array}$ & $\begin{array}{c}3.4 \\
( \pm 0.3)\end{array}$ & $\begin{array}{c}-5.65 \\
( \pm 0.04)\end{array}$ & $\begin{array}{c}3.7 \\
( \pm 1.1)\end{array}$ & $\begin{array}{c}-5.60 \\
( \pm 0.13)\end{array}$ & $\begin{array}{c}0.589 \\
( \pm 0.017)\end{array}$ & $\begin{array}{c}0.512(+0.078 /- \\
0.061)\end{array}$ \\
\hline $\begin{array}{l}\text { GRA- } \\
17\end{array}$ & $\begin{array}{l}171 \\
( \pm 2)\end{array}$ & $\begin{array}{c}3.02 \\
( \pm 0.11)\end{array}$ & $\begin{array}{c}3.0 \\
( \pm 0.6)\end{array}$ & $\begin{array}{c}-5.70 \\
( \pm 0.09)\end{array}$ & $\begin{array}{r}\text { Low sign } \\
\text { ra }\end{array}$ & $\begin{array}{l}\text { l-to-noise } \\
\text { io }\end{array}$ & $\begin{array}{c}0.432 \\
( \pm 0.015)\end{array}$ & $\begin{array}{c}0.567(+0.041 /- \\
0.093)\end{array}$ \\
\hline $\begin{array}{c}\text { GRA- } \\
18\end{array}$ & $\begin{array}{l}245 \\
( \pm 3)\end{array}$ & $\begin{array}{c}1.99 \\
( \pm 0.07)\end{array}$ & $\begin{array}{c}7.5 \\
( \pm 0.4)\end{array}$ & $\begin{array}{c}-5.32 \\
( \pm 0.02)\end{array}$ & $\begin{array}{r}\text { Low sign } \\
\text { ra }\end{array}$ & $\begin{array}{l}\text { l-to-noise } \\
\text { io }\end{array}$ & $\begin{array}{c}0.276 \\
( \pm 0.013)\end{array}$ & $\begin{array}{c}0.260(+0.013 /- \\
0.020)\end{array}$ \\
\hline $\begin{array}{c}\text { GRA- } \\
19\end{array}$ & $\begin{array}{c}875 \\
( \pm 36)\end{array}$ & 4 & $\begin{array}{c}9.1 \\
( \pm 2.0)\end{array}$ & $\begin{array}{c}-5.24 \\
( \pm 0.09)\end{array}$ & $\begin{array}{r}\text { Low sign } \\
\text { ra }\end{array}$ & $\begin{array}{l}\text { l-to-noise } \\
\text { io }\end{array}$ & $\begin{array}{c}0.097 \\
( \pm 0.014)\end{array}$ & $\begin{array}{c}0.153(+0.069 /- \\
0.037)\end{array}$ \\
\hline $\begin{array}{l}\text { GRA- } \\
\text { BR }\end{array}$ & $\begin{array}{c}433 \\
( \pm 11)\end{array}$ & 4 & $\begin{array}{c}5.0 \\
( \pm 0.5)\end{array}$ & $\begin{array}{c}-5.49 \\
( \pm 0.04)\end{array}$ & $\begin{array}{r}\text { Low sign } \\
\text { ra }\end{array}$ & $\begin{array}{l}\text { l-to-noise } \\
\text { io }\end{array}$ & $\begin{array}{c}0.234 \\
( \pm 0.036)\end{array}$ & $\begin{array}{c}0.376(+0.028 /- \\
0.037)\end{array}$ \\
\hline $\begin{array}{l}\text { SOG- } \\
02\end{array}$ & $\begin{array}{c}688 \\
( \pm 16)\end{array}$ & $\begin{array}{c}1.57 \\
( \pm 0.13)\end{array}$ & $\begin{array}{c}8.6 \\
( \pm 0.2)\end{array}$ & $\begin{array}{c}-5.26 \\
( \pm 0.01)\end{array}$ & $\begin{array}{r}\text { Low sign } \\
\text { ra }\end{array}$ & $\begin{array}{l}\text { l-to-noise } \\
\text { io }\end{array}$ & $\begin{array}{c}0.172 \\
( \pm 0.010)\end{array}$ & $\begin{array}{c}0.229(+0.015 /- \\
0.017)\end{array}$ \\
\hline $\begin{array}{l}\text { SOG- } \\
06\end{array}$ & $\begin{array}{l}613 \\
( \pm 8)\end{array}$ & $\begin{array}{c}1.41 \\
( \pm 0.07)\end{array}$ & $\begin{array}{c}4.3 \\
( \pm 0.1)\end{array}$ & $\begin{array}{c}-5.54 \\
( \pm 0.01)\end{array}$ & $\begin{array}{c}5.1 \\
( \pm 1.0)\end{array}$ & $\begin{array}{c}-5.47 \\
( \pm 0.08)\end{array}$ & $\begin{array}{c}0.409 \\
( \pm 0.044)\end{array}$ & $\begin{array}{c}0.444(+0.09 /- \\
0.019)\end{array}$ \\
\hline $\begin{array}{c}\text { SOG- } \\
10\end{array}$ & $\begin{array}{c}588 \\
( \pm 10)\end{array}$ & $\begin{array}{c}1.75 \\
( \pm 0.09)\end{array}$ & $\begin{array}{c}4.6 \\
( \pm 0.1)\end{array}$ & $\begin{array}{c}-5.52 \\
( \pm 0.01)\end{array}$ & $\begin{array}{c}4.6 \\
( \pm 0.7)\end{array}$ & $\begin{array}{c}-5.52 \\
( \pm 0.06)\end{array}$ & $\begin{array}{c}0.403 \\
( \pm 0.050)\end{array}$ & $\begin{array}{c}0.444(+0.010 /- \\
0.013)\end{array}$ \\
\hline $\begin{array}{c}\text { SOG- } \\
17\end{array}$ & $\begin{array}{l}384 \\
( \pm 6)\end{array}$ & $\begin{array}{c}1.87 \\
( \pm 0.09)\end{array}$ & $\begin{array}{c}3.7 \\
( \pm 0.1)\end{array}$ & $\begin{array}{c}-5.61 \\
( \pm 0.01)\end{array}$ & $\begin{array}{c}5.2 \\
( \pm 0.3)\end{array}$ & $\begin{array}{l}-5.47 \\
( \pm 0.02)\end{array}$ & $\begin{array}{c}0.294 \\
( \pm 0.019)\end{array}$ & $\begin{array}{c}0.448(+0.006 /- \\
0.005)\end{array}$ \\
\hline $\begin{array}{l}\text { SOG- } \\
21\end{array}$ & $\begin{array}{c}717 \\
( \pm 10)\end{array}$ & $\begin{array}{c}2.21 \\
( \pm 0.08)\end{array}$ & $\begin{array}{c}8.5 \\
( \pm 0.1)\end{array}$ & $\begin{array}{l}-5.27 \\
( \pm 0.01)\end{array}$ & $\begin{array}{l}11.1 \\
( \pm 0.5)\end{array}$ & $\begin{array}{l}-5.16 \\
( \pm 0.02)\end{array}$ & $\begin{array}{c}0.164 \\
( \pm 0.009)\end{array}$ & $\begin{array}{c}0.180(+0.011 /- \\
0.010)\end{array}$ \\
\hline $\begin{array}{l}\text { SOG- } \\
22\end{array}$ & $\begin{array}{l}236 \\
( \pm 5)\end{array}$ & $\begin{array}{c}1.30 \\
( \pm 0.06)\end{array}$ & $\begin{array}{c}4.0 \\
( \pm 0.3)\end{array}$ & $\begin{array}{l}-5.57 \\
( \pm 0.03)\end{array}$ & $\begin{array}{c}3.2 \\
( \pm 0.4)\end{array}$ & $\begin{array}{l}-5.67 \\
( \pm 0.05)\end{array}$ & $\begin{array}{c}0.519 \\
( \pm 0.022)\end{array}$ & $\begin{array}{c}0.480(+0.049 /- \\
0.023)\end{array}$ \\
\hline SOG- & 567 & 2.11 & 5.2 & -5.47 & 4.8 & -5.50 & 0.359 & $0.408(+0.057 /-$ \\
\hline
\end{tabular}




\begin{tabular}{|ccc|cccc|cc|}
$\mathbf{2 5}$ & $( \pm 12)$ & $( \pm 0.13)$ & $( \pm 1.3)$ & $( \pm 0.10)$ & $( \pm 2.1)$ & $( \pm 0.18)$ & $( \pm 0.016)$ & $0.108)$ \\
SOG- & 552 & 2.19 & 3.9 & -5.58 & 4.5 & -5.52 & 0.439 & $0.446(+0.049 /-$ \\
$\mathbf{3 8}$ & $( \pm 9)$ & $( \pm 0.11)$ & $( \pm 1.1)$ & $( \pm 0.12)$ & $( \pm 0.5)$ & $( \pm 0.04)$ & $( \pm 0.020)$ & $0.027)$ \\
\hline YAK- & 349 & 1.72 & 12.6 & -5.12 & Low signal-to-noise & 0.034 & $0.094(+0.039 /-$ \\
03 & $( \pm 15)$ & $( \pm 0.23)$ & $( \pm 1.6)$ & $( \pm 0.05)$ & \multicolumn{2}{c}{ ratio } & $( \pm 0.008)$ & $0.020)$ \\
YAK- & 276 & 1.51 & 4.1 & -5.56 & 4.1 & -5.56 & 0.011 & $0.443(+0.112 /-$ \\
07 & $( \pm 6)$ & $( \pm 0.08)$ & $( \pm 0.4)$ & $( \pm 0.04)$ & $( \pm 2.3)$ & $( \pm 0.24)$ & $( \pm 0.008)$ & $0.132)$ \\
YAK- & 194 & 1.70 & 3.3 & -5.65 & 3.1 & -5.67 & 0.549 & $0.577(+0.022 /-$ \\
09 & $( \pm 3)$ & $( \pm 0.06)$ & $( \pm 0.3)$ & $( \pm 0.04)$ & $( \pm 0.3)$ & $( \pm 0.05)$ & $( \pm 0.018)$ & $0.039)$ \\
YAK- & 431 & 2.44 & 5.5 & -5.44 & 7.4 & -5.32 & 0.250 & $0.289(+0.046 /-$ \\
$\mathbf{1 3}$ & $( \pm 13)$ & $( \pm 0.21)$ & $( \pm 0.4)$ & $( \pm 0.03)$ & $( \pm 1.7)$ & $( \pm 0.09)$ & $( \pm 0.023)$ & $0.025)$ \\
YAK- & 271 & 2.32 & 4.1 & -5.56 & Low signal-to-noise & 0.427 & $0.447(+0.045 /-$ \\
$\mathbf{1 5}$ & $( \pm 11)$ & $( \pm 0.29)$ & $( \pm 0.5)$ & $( \pm 0.05)$ & ratio & $( \pm 0.071)$ & $0.024)$ \\
YAK- & 443 & & 6.8 & -5.36 & Low signal-to-noise & 0.125 & $0.254(+0.017 /-$ \\
$\mathbf{1 7}$ & $( \pm 22)$ & 4 & $( \pm 0.5)$ & $( \pm 0.03)$ & ratio & $( \pm 0.036)$ & $0.020)$ \\
YAK- & 405 & 2.24 & 8.1 & -5.29 & 5.5 & -5.44 & 0.204 & $0.282(+0.024 /-$ \\
$\mathbf{1 8}$ & $( \pm 7)$ & $( \pm 0.11)$ & $( \pm 0.4)$ & $( \pm 0.02)$ & $( \pm 1.0)$ & $( \pm 0.08)$ & $( \pm 0.007)$ & $0.020)$ \\
YAK- & 905 & & 7.2 & -5.33 & Low signal-to-noise & 0.121 & $0.233(+0.019 /-$ \\
$\mathbf{1 9}$ & $( \pm 13)$ & 4 & $( \pm 0.6)$ & $( \pm 0.03)$ & \multicolumn{2}{c}{ ratio } & $( \pm 0.014)$ & $0.022)$ \\
YAK- & 390 & 2.36 & 4.1 & -5.57 & 3.3 & -5.66 & 0.124 & $0.476(+0.090 /-$ \\
$\mathbf{5 0}$ & $( \pm 7)$ & $( \pm 0.12)$ & $( \pm 0.3)$ & $( \pm 0.03)$ & $( \pm 1.1)$ & $( \pm 0.15)$ & $( \pm 0.005)$ & $0.038)$ \\
\hline
\end{tabular}

Notes. Dose response curves (with recycling ratio within $10 \%$ of unity) have been fitted using the General-Order Kinetics GOK function (Guralnik et al., 2015a,c), to obtain the characteristic dose $\mathrm{D}_{0}$ and the kinetic order $\alpha$ (note: a limiting value of $\alpha=4$ was adopted for a few datasets which did not exhibit sufficient flattening off of the luminescence signal at high doses). Fading decay curves were fitted (a) following Huntley and Lamothe (2001) to obtain the g-value (normalized to 2 days); (b) following Huntley (2006) to obtain the density of recombination centres $\rho^{\prime}$ (reported as $\log _{10} \rho^{\prime}$ ), assuming an escape frequency factor of $3 \times 10^{15} \mathrm{~s}^{-1}$ (Huntley, 2006). Results of the short-shine method were accepted only when there existed two replicates with acceptable signal to noise ratio (luminescence signal ten times higher than background). Natural trap filling ( $\mathrm{n} / \mathrm{N}_{\mathrm{nat}}$; reported as mean and std. dev.) and predicted field saturation ( $\mathrm{n} / \mathrm{N}_{\mathrm{ss}}$; reported as median and $68 \%$ conf. int.) were derived following Guralnik et al. (2015a), the latter using a Monte-Carlo approach (1000 iterations, each with randomized input of the kinetic parameters and the dose rate; note that wherever possible, an average $\rho^{\prime}$ between the long- and short-shine experiments was used). Laboratory dose rates vary between 0.099 and $0.207 \mathrm{~Gy} \mathrm{~s}^{-1}$ for the different instruments used. 

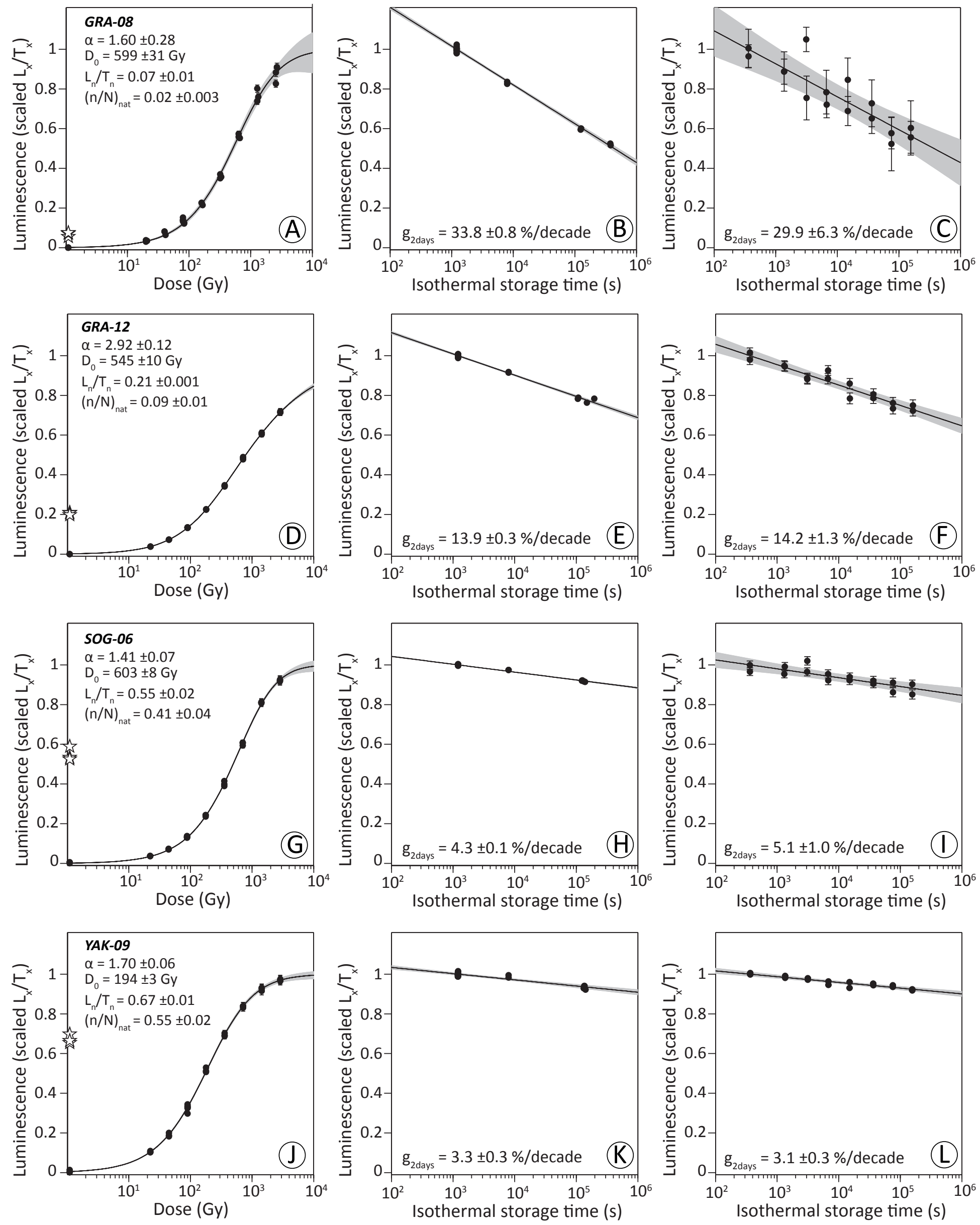
Figure_2




Figure_3

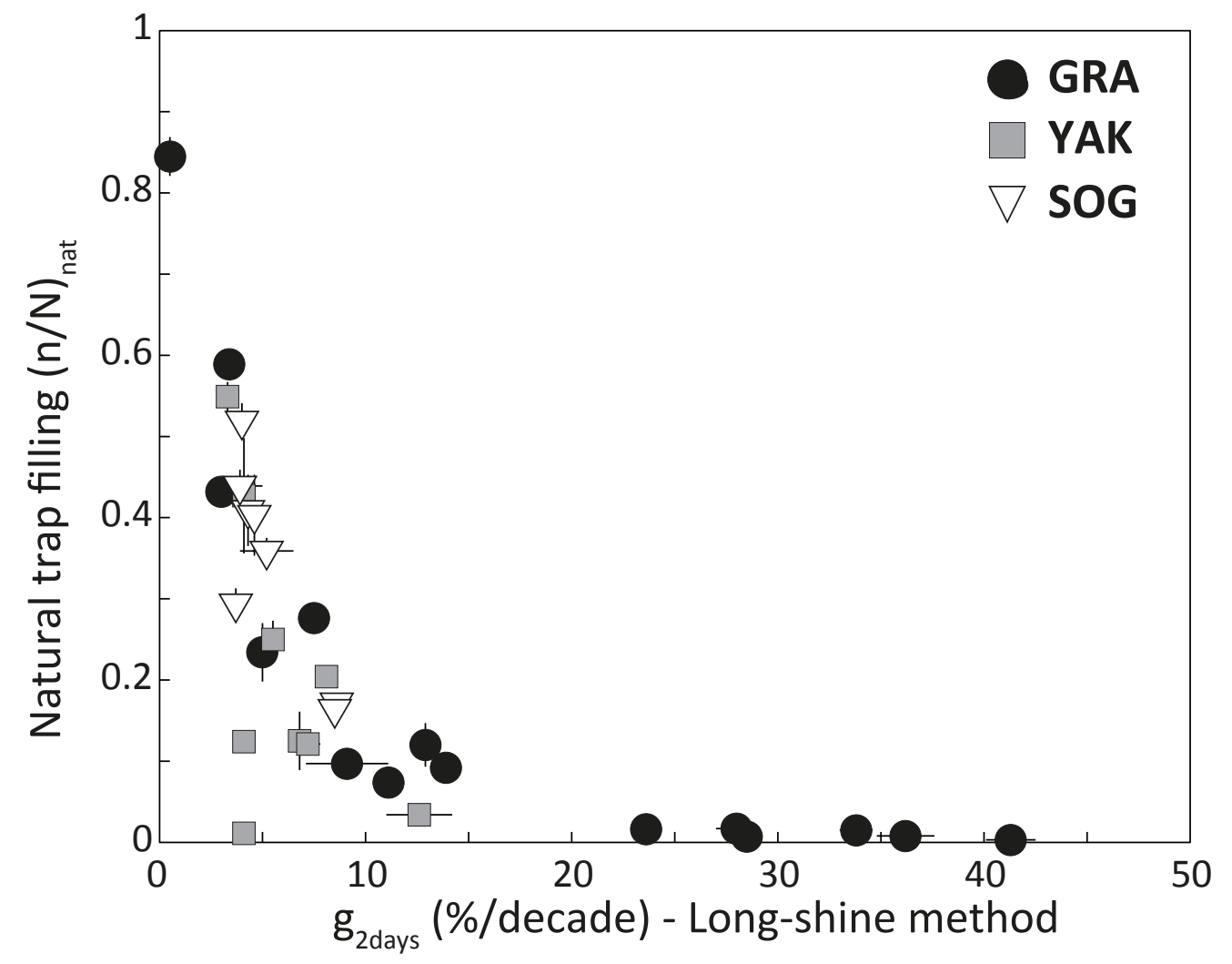


Figure_4
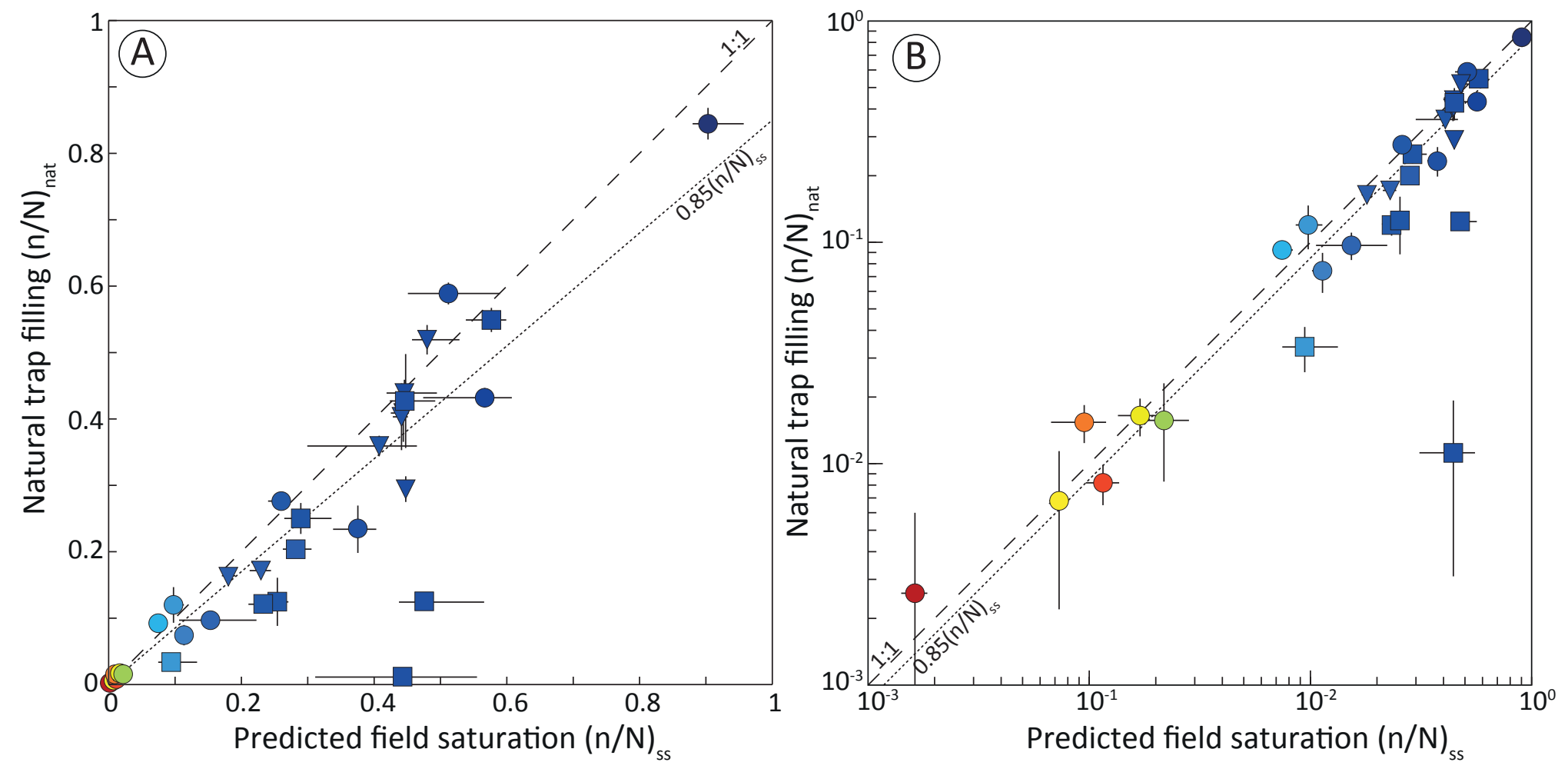

$\bigcirc$ GRA $\square$ YAK

$\nabla$ SOG

$\begin{array}{llccc}0 & 10 & 20 & 30 & 40 \\ & \mathbf{g}_{\text {2days }} \text { (\%/decade) } & \end{array}$ 
Figure_5
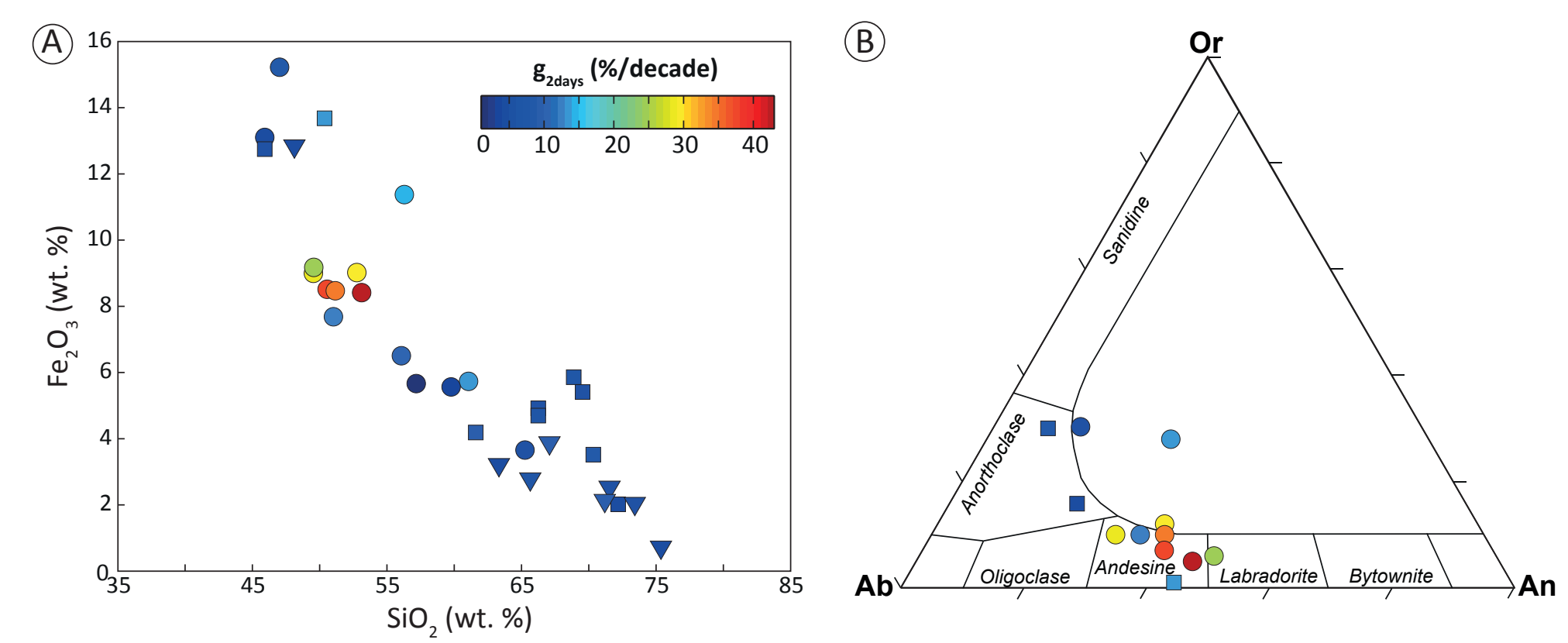